\title{
Product Market Deregulation and Labor Market Outcomes*
}

\author{
Monique Ebell ${ }^{\dagger}$ \\ Christian Haefke $\ddagger$
}

First Version: December 2002

This Version: December 2003

\begin{abstract}
We consider the dynamic relationship between product market entry regulation and equilibrium unemployment. The main theoretical contribution is combining a Mortensen-Pissarides model with monopolistic competition in the goods market and individual wage bargaining. Product market competition affects unemployment via two channels: the output expansion effect and a countervailing effect due to a hiring externality. Competition is then linked to barriers to entry. A calibrated model compares a high-regulation European regime to a low-regulation Anglo-American one. Our quantitative analysis suggests that under individual bargaining, no more than half a percentage point of European unemployment rates can be attributed to entry regulation.
\end{abstract}

JEL Codes: E24, J63, L16, O00

Keywords: Product market competition, barriers to entry, wage bargaining, European Unemployment Puzzle

*We thank Philippe Bacchetta, Jan Boone, Michael Burda, Antonio Cabrales, Jordi Galí, Katharina Greulich, Adriana Kugler, Pietro Peretto, Chris Pissarides, Albrecht Ritschl, Roberto Samaniego, Eric Smith, Chris Telmer, and Harald Uhlig, for helpful discussions. We also thank seminar audiences at Cambridge University, Duke University, the European Central Bank, Humboldt, IZA, Tilburg, UPF, and Universitat Autonoma de Barcelona, as well as the participants of the 2003 North American Winter Meetings of the Econometric Society, the CEPR DAEUP meeting in Berlin and the 2003 SED meetings for helpful comments. All remaining errors are our own. Haefke acknowledges financial support from EU grant HPMF-CT-2001-01252 and CICYT grant SEC2001-0792.

${ }^{\dagger}$ Humboldt University of Berlin and Study Center Gerzensee, email: ebell@wiwi.hu-berlin.de

†Universitat Pompeu Fabra, CREA and IZA, email: christian.haefke@upf.edu 


\section{Introduction}

A growing body of recent literature attempts to explain the divergent performance of European and US labor markets during the 80's and 90's. Generally, the focus has been upon interactions of labor market institutions with other economic variables [cf. Ljungqvist and Sargent (1998,2004), den Haan, Haefke, and Ramey (2001)] and upon hiring and firing restrictions. However, relatively little attention has been paid to one of the primary ways in which US and European economies differ: the degree of product market regulation. To give an idea of the magnitudes involved, Table 1 presents an index of barriers to entry in the US and in the European Union, compiled by Fonseca, Lopez and Pissarides (2001) and based on OECD data. The index combines the average time required to establish a standardized firm with the number of procedures necessary into a weeks-based measure of entry delay. The measured delays range from 8.6 business days in the United States to a whopping 85 days in Spain. The population-weighted EU average of 54.7 days is many times larger than the corresponding American figure. Djankov, et.al. (2002) report data on a second dimension of entry barriers, namely the pecuniary cost of establishing a standardized firm as a percentage of the per capita GDP of the respective country. This data is also reproduced in Table 1. Once again, the gulf between the AngloAmerican world and Europe is striking: establishing a firm in the US costs less than 1\% of per capita GDP, while establishing the average continental European firm costs $18.4 \%$ of per capita GDP. The European barriers to entry are an order of magnitude larger. Table 1 also compares the Fonseca et. al. index to Djankov, et. al.'s independent data on entry delay: it is easy to see that both data sources tell the same story. Continental European barriers to entry are substantially higher than those in the Anglo-American countries. It seems reasonable that such large differences in entry barriers might translate into large differences in labor market outcomes. Krueger and Pischke (1997) also conjecture that large parts of the U.S. American employment miracle can be attributed to its flexible product markets.

Indeed, there is a growing body of empirical evidence to support the link between product market regulation and labor markets. Bertrand and Kramarz (2002) examine the impact of French legislation ${ }^{1}$, which regulated entry into French retailing. They find that those regions (departements) which restricted entry more strongly, experienced slower rates of job growth. Boeri, Nicoletti and Scarpetta (2000), using an OECD index of the degree of product market regulation, also report a negative relationship between their regulation measure and employment. Fonseca, et. al. (2001) show that their index of entry barriers is negatively correlated with employment and positively correlated with unemployment rates. Moreover, the timing of US deregulation efforts, which began in the late 1970's, fits neatly into the picture of labor market performance which began to diverge in the early 80 's. The most important pieces of US deregulation were put into place in the late 70's and early 80's. These measures were accompanied by an overall push to reduce "red tape". In contrast, European deregulation efforts are still incipient. Hence, product market deregulation is a sort of smoking gun for divergent US and European labor market performance, whose implications are worth investigating.

Relatively little previous theoretical work has analyzed whether and how product market rigidities may affect equilibrium labor market outcomes. Nickell (1999) provides an insightful overview of early work which is either

\footnotetext{
${ }^{1}$ Loi Royer of 1974
} 
partial equilibrium or employing some form of collective bargaining. Recent important contributions are the papers of Pissarides (2001) and Blanchard and Giavazzi (2003). Pissarides (2001) focuses on the impact of entry barriers on the decision to become an entrepreneur or a worker, finding that entry barriers can indeed lead to lower rates of entrepreneurship and hence job creation, and ultimately to higher rates of equilibrium unemployment. However, those firms which have overcome the barriers to entry then face perfect competition. In contrast, Blanchard and Giavazzi (2003) study labor market outcomes in a model with monopolistic competition but with a more stylized labor-market setting. They find that equilibrium unemployment is decreasing in the degree of product market competition, and also emphasize that equilibrium wages are increasing in the degree of product market competition. In a similar vein, Spector (2002) studies the effects of changes in the intensity of product market competition in a model with capital and concludes that product-market and labor-market regulations tend to reinforce each other. The latter two papers consider static or two-period setups.

We contribute to the product market/labor market debate by specifying a fully dynamic matching model which we believe to be very well suited for both the theoretical and the quantitative study of product- and labor market issues. Our model combines monopolistic competition in the goods market with fully-microfounded unemployment arising from Mortensen-Pissarides-style matching frictions. To allow firms to adjust output in response to varying degrees of product market competition [as predicted by first principles], we allow for multi-worker firms. Wages are the result of pairwise Nash bargaining between individual workers and firms. This individual Nash-bargaining setup has been shown by Stole and Zwiebel $(1996,1996 a)$ to be the appropriate one for multi-worker firms, in the sense that pairwise individual bargaining is representable as a Binmore-Rubinstein-Wolinsky alternating offer game, providing a microfoundation for the use of Nash bargaining.

We use our model in two ways. First, we investigate the link between the degree of product market competition and the labor market equilibrium both theoretically and quantitatively, with a special focus on the equilibrium unemployment rate. We identify two main channels by which competition affects unemployment. The first is the output expansion effect. From first principles, firms with monopoly power maximize profits by restricting output with respect to its full-competition level. As competition increases, profit-maximizing output expands, and along with it the demand for labor. This in turn implies a greater rate of vacancy creation,which leads to a lower rate of unemployment. The second channel is due to the effects of competition on individual wage-bargaining and is countervailing. As will be explained in detail in section 2, individual bargaining gives firms an incentive to hire more than the socially efficient number of workers, as first noted by Stole and Zwiebel (1996, 1996a). We show that this overhiring effect is strongest at low levels of competition. As competition increases, overhiring is diminished, placing downward pressure on vacancy creation and counteracting the output expansion effect.

The degree to which the overhiring effect will be able to eat away at the output-expansion effects of increasing competition is ultimately a quantitative question, which we address in Sections 4 and 5. Quantitatively, we will find that the overhiring effect is indeed strong, in the sense that it does counteract most of the output expansion effect on equilibrium unemployment. As a result, the impact of product market competition on equilibrium unemployment turns out to be surprisingly weak under individual bargaining. In our benchmark calibration, unemployment falls by 
only about two percentage points when the demand elasticity facing individual firms is increased fivefold. Increasing the elasticity even further has only negligible impact on labor market variables. Hence we conclude: a little bit of competition goes a long way. Our result is fully consistent with the empirical results of Bresnahan and Reiss (1991), who find that "once the market has between three and five firms, the next entrant has little effect on competitive conduct".

In qualitative terms, our results are quite similar to those of Blanchard and Giavazzi (2003), Fonseca, et. al. (2001) and Pissarides (2001). We confirm both authors' results on the benefits of product market competition for lowering equilibrium unemployment rates. We also confirm Blanchard and Giavazzi's finding that greater degrees of product market competition lead to higher real wages. In addition, we find these wage increases to be quantitatively substantial. The move from a US-style to a European-style regulatory regime would lead to an increase in net real wages of about $11 \%$, lending support to Blanchard and Giavazzi's argument that product market reform could be used as a sort of spoonful of sugar to help the medicine of labor market reform go down more easily.

The second way in which we apply our model is to study the link between entry barriers and the labor market equilibrium. Introducing entry barriers allows us to endogenize the degree of product market competition. We calibrate the model using the previously cited data on barriers to entry, and investigate the quantitative impact of barriers to entry on equilibrium unemployment. In particular, we ask how much of the difference in US and continental European unemployment rates can be explained by the observed differences in barriers to entry. We find that the substantial differences in entry barriers can only account for a surprisingly small difference in equilibrium unemployment rates of less than one-half of a percentage point. By means of comparison, the unemployment differential generated by observed differences in replacement rates [unemployment benefits] is more than six times as large. This surprising result is due to the countervailing impact of individual bargaining. Hence, we conclude that individual wage-bargaining is able to substantially mitigate the impact of firms' monopoly power, and hence also mitigate the negative impact of entry regulation. ${ }^{2}$

Finally, we are able to contribute to the recent discussion on the robustness of Stole and Zwiebel (1996a)'s overhiring results to the presence of a pool of replacement workers. In a partial equilibrium setting, De Fontenay and Gans (2003) show that the availability of a finite pool of replacement workers with given reservation wage reverses Stole and Zwiebel's overhiring effect under individual bargaining. They argue that there is no need to actually hire additional workers to depress wages, since the threat of replacing them from the pool of alternative workers is sufficient to put downward pressure wages. In their reply, Stole and Zwiebel (2003) note that a general equilibrium analysis would be necessary to address this issue more conclusively. We provide just such a general equilibrium analysis, in which optimal firm size, as well as the size of the pool of available replacement workers (the unemployed) and their reservation wages are determined endogenously. We find that Stole and Zwiebel (1996a)'s hiring externality does indeed survive the transition to general equilibrium and replaceable workers, in the sense that profit-maximizing firms do indeed expand hiring in a (successful) attempt to depress wages. In addition, we find evidence for the presence

\footnotetext{
${ }^{2}$ In a companion paper, we investigate under which circumstances individual bargaining is robust to the formation of collective bargaining coalitions.
} 
of overhiring, in the sense that workers' equilibrium wages may exceed their marginal (revenue) product to the firm. However, we also find that the hiring externality arises only in the presence of imperfect product market competition, and that the net effect of imperfect competition and individual bargaining is underhiring.

The remainder of the paper is organized as follows: Section 2 presents the basic model. Section 3 characterizes short and long-run equilibrium, and presents analytic results on the impact of product market competition on labor market equilibrium. Section 4 focuses on quantitative analysis, and examines the ability of observed differences in entry barriers to account for the gap between US and continental European unemployment rates. Section 5 explores the constrained Pareto efficiency properties of our model, while Section 6 concludes.

\section{The Basic Model}

In this section we present the basic general equilibrium model. Its main elements are monopolistic competition in the goods market and Mortensen-Pissarides-style matching in the labor market. Our innovation lies in defining and solving the multi-worker firm's problem under monopolistic competition and individual bargaining. The households' problems are standard. We restrict our analysis to the steady state.

\subsection{Households}

\subsubsection{Search and Matching in the Labor Market}

The labor market is characterized by a standard search and matching framework (e.g. Pissarides, 2000). Unemployed workers $u$ and vacancies $v$ are converted into matches by a constant returns to scale matching function ${ }^{3} m(u, v)=$ $s \cdot u^{\eta} v^{1-\eta}$. Defining labor market tightness as $\theta \equiv \frac{v}{u}$, the firm meets unemployed workers at rate $q(\theta)=s \theta^{-\eta}$, while the unemployed workers meet vacancies at rate $\theta q(\theta)=s \theta^{1-\eta}$.

In the basic model, workers and firms are identical so that all jobs are identical. For each worker, the value of employment is given by $V^{E}$, which satisfies ${ }^{4}$ :

$$
r V^{E}=w-\chi\left[V^{E}-V^{U}\right]
$$

where $\chi$ is the total separation rate, $w$ denotes the per period nominal wage, and $V^{U}$ the value of being unemployed. Firms and workers may separate either because the match is destroyed, which occurs with probability $\tilde{\chi}$ or because the firm has exited, which occurs with probability $\delta$. We assume that these two sources of separation are independent, so that the total separation probability is given by $\chi=\tilde{\chi}+\delta-\tilde{\chi} \delta$. Explicit firm exit is incorporated mainly for

\footnotetext{
${ }^{3}$ As is quite standard in the literature, $s$ denotes a scaling parameter which serves to bring matching rates within the [0,1] interval, while $\eta$ denotes the elasticity of matches with respect to the number of unemployed.

${ }^{4} \mathrm{We}$ assume that all payments are made at the end of a period so that our value functions in discrete time actually coincide with their continuous time counterpart. Equation (1) can be obtained from

$$
r V^{E}=\frac{1}{1+r}\left(w+(1-\chi) V^{E}+\chi V^{U}\right)
$$
}


quantitative reasons. If firms were counterfactually infinitely lived, then the impact of a given level of entry costs would be greatly understated, since firms could amortize those entry costs over an infinite lifespan.

The value of unemployment is standard and is the same for all workers:

$$
r V^{U}=b P+\theta q(\theta)\left[V^{E}-V^{U}\right]
$$

where $P$ denotes the aggregate price level and $b$ real unemployment benefits.

\subsubsection{Monopolistic Competition in the Goods Market}

Households are both consumers and workers. As consumers they are risk neutral in the aggregate consumption good. Agents have Dixit-Stiglitz preferences over a continuum of differentiated goods. Goods demand each period is derived from the household's optimization problem:

$$
\max \left(\int c_{i, n}^{\frac{\sigma-1}{\sigma}} d i\right)^{\frac{\sigma}{\sigma-1}}
$$

subject to the budget constraint $I_{n}=\int c_{i} \frac{P_{i}}{P} d i$ where $I_{n}$ denotes the real income of household $n$ and $c_{i, n}$ is household $n$ 's consumption of good $i$. In order to focus the dynamics on the labor market, there is no saving. Thus we obtain aggregate demand for good $i$ given as:

$$
Y_{i}^{D} \equiv \int c_{i, n} d n=\left(\frac{P_{i}}{P}\right)^{-\sigma} I,
$$

where $I \equiv \int I_{n} \mathrm{~d} n$ is aggregate real income and $P=\left(\int P_{i}^{\frac{\sigma-1}{\sigma}}\right)^{\frac{\sigma}{\sigma-1}}$ is the price index. Equation (4) is the standard monopolistic-competition demand function with elasticity of substitution among differentiated goods given by $-\sigma$.

\subsection{Modeling Competition}

In principle, there are two ways in which greater competition may manifest itself: as greater competition within each industry or as greater competition among industries. Greater competition among industries would imply an increase in the elasticity of substitution among differentiated goods $\sigma$. In fact Bertrand and Kramarz (2002) find some evidence for increased product differentiation in the French retail industry in response to the Loi Royer. However, it is often argued that $\sigma$ is a preference parameter rather than a measure of competition. We address this concern in the basic model by treating $\sigma$ as a fixed preference parameter. That is, we will not rely on variations in $\sigma$ to model differing degrees of competition. Rather, we follow Galí (1995) in assuming that each differentiated good $i$ is produced by an industry populated by $n_{i}$ firms. An increase in the number of firms in each industry leads to an increase in the degree of competition within each industry, as captured by an increase in the demand elasticity faced by each individual firm.

The firms within each industry compete by Cournot. ${ }^{5}$ Under Cournot competition, firm $j$ in industry $i$ has output $Y_{i j}$ which satisfies:

$$
Y_{i}^{S}=Y_{i j}+\left(n_{i}-1\right) \bar{Y}_{i,-j}
$$

\footnotetext{
${ }^{5}$ In the basic model, we focus on the collusion-free equilibrium of the dynamic Cournot game. Collusive equilibria would involve even greater output restriction at each industry size, which would strengthen our results.
} 
where $Y_{i}^{S}$ is aggregate supply of good $i$ and $\bar{Y}_{i,-j}$ is the average output of firm j's $n_{i}-1$ competitors. From (4), firm $j$ faces demand function

$$
\frac{P_{i}\left(Y_{i j} \mid n_{i}, \bar{Y}_{i,-j}\right)}{P}=\left(\frac{Y_{i j}+\left(n_{i}-1\right) \bar{Y}_{i,-j}}{I}\right)^{-\frac{1}{\sigma}}
$$

This leads to a definition of firm-level elasticity of demand as:

$$
\xi_{i j} \equiv-\frac{\partial Y_{i j}}{\partial P_{i}} \cdot \frac{P_{i}}{Y_{i j}}=\sigma\left[1+\frac{\left(n_{i}-1\right) \bar{Y}_{i,-j}}{Y_{i j}}\right] .
$$

When firms within an industry are symmetric, each firm faces a demand elasticity which depends only on the total number of firms present in the industry:

$$
\xi_{i}=n_{i} \sigma
$$

In the basic model we will assume symmetric firms in equilibrium. In what follows we will label firms only by their industry $i{ }^{6}$

Our competition framework turns out to be very flexible and tractable. The equilibrium condition will turn out to depend only upon $\xi_{i}$, and not upon $\sigma$ or $n_{i}$ independently. Hence, it becomes equivalent to vary competition by varying industry size, holding $\sigma$ constant, or to vary competition by varying the elasticity of substitution across differentiated goods $\sigma$, holding industry size constant, as in Blanchard and Giavazzi (2003).

\subsection{Multiple-worker Firms}

The standard Mortensen-Pissarides setup assumes one-worker firms. Under perfect competition in goods markets, this assumption is harmless, since the number and size of firms is indeterminate. Under monopolistic competition, however, firms react to downward sloping demand by restricting output. The only way to vary output with a given technology is to vary the amount of labor employed either on the intensive margin or on the extensive margin. ${ }^{7}$ Consistent with stylized facts we assume that firms adjust employment by varying the number of workers [extensive margin] rather than the number of hours per worker. In our multi-worker firm model the number of workers employed is determined endogenously, as a function of the elasticity of demand $\xi_{i}$.

Firms maximize the discounted value of future profits. Firm $i$ 's state variable is the number of workers currently employed, $H_{i}$. The firm's key decision is the number of vacancies. Firms open as many vacancies as necessary to hire in expectation the desired number of workers next period, while taking into account that the real cost to opening a vacancy is $\Phi_{V}$. The firm's problem becomes:

$$
V^{J}\left(H_{i}\right)=\max _{H_{i}^{\prime}, v_{i}} \frac{1}{1+r}\left\{P_{i}\left(Y_{i}\right) Y_{i}-w\left(H_{i}\right) H_{i}-\Phi_{V} P v_{i}+(1-\delta) V^{J}\left(H_{i}^{\prime}\right)\right\}
$$

subject to

$$
\text { demand function: } \quad \frac{P_{i}\left(Y_{i}\right)}{P}=\left(\frac{Y_{i}+\left(n_{i}-1\right) \bar{Y}_{i}}{I}\right)^{-\frac{1}{\sigma}}
$$

\footnotetext{
${ }^{6}$ To avoid confusion, we denote aggregate demand facing industry $i$ by $Y_{i}^{D}$, while industry $i$ 's aggregate supply is denoted $Y_{i}^{S}$ and the output of an individual firm in industry $i$ is denoted $Y_{i}$.

${ }^{7}$ In a model with capital, firms could also vary output by varying only the amount of capital employed. In order to maintain an optimal capitallabor ratio, however, firms would also generally adjust by varying labor as well.
} 


$$
\begin{aligned}
\text { production function: } & Y_{i}=A H_{i} \\
\text { transition function: } & H_{i}^{\prime}=(1-\widetilde{\chi}) H_{i}+q(\theta) v_{i} \\
\text { wage curve: } & w\left(H_{i}\right)
\end{aligned}
$$

where the wage curve is subject to individual bargaining as described in section 2.4.1. The firm's problem takes into account that a measure $\delta$ of firms exits each period.

Although the multi-worker firm problem may appear daunting at first glance, the first order condition is refreshingly simple:

$$
\frac{\Phi_{V} P}{q(\theta)} \frac{1}{1-\delta}=\frac{\partial V^{J}\left(H_{i}^{\prime}\right)}{\partial H_{i}^{\prime}} .
$$

By (14), the marginal value of an additional worker must equal the cost of searching for him/her, weighted by the probability of firm survival $1-\delta$, neither of which is firm-specific.

Combining (14) with the envelope condition, using the definition of demand elasticity (7) and rearranging, yields a simple mark-up expression for the relative price of firm $i$ 's good:

$$
\frac{P_{i}\left(H_{i}\right)}{P}=\frac{\xi_{i}}{\xi_{i}-1}\left\{\left[\frac{w\left(H_{i}\right)}{P}+\frac{\Phi_{V}}{q(\theta)}\left(\frac{r+\chi}{1-\delta}\right)+H_{i} \frac{\partial\left[w\left(H_{i}\right) / P\right]}{\partial H_{i}}\right] \frac{1}{A}\right\} .
$$

where $\xi_{i}$ is the firm-level elasticity of demand. Firms price their goods by taking a constant markup $\frac{\xi_{i}}{\xi_{i}-1}$ on the marginal cost of producing the good (the term in curly brackets). The marginal cost of labor (in square brackets) has three terms: the unit labor cost $\frac{w\left(H_{i}\right)}{P}$, the annuitized search $\operatorname{cost} \frac{\Phi_{V}}{q(\theta)}\left(\frac{r+\chi}{1-\delta}\right)$, and the effect on the wage from hiring another worker $H_{i} \frac{\partial\left[w\left(H_{i}\right) / P\right]}{\partial H_{i}}$. The final term reflects firms' correct anticipation that the result of wage bargaining will depend upon the number of workers hired. In addition, it is useful to note that (15) is an implicit labor demand expression that relates the firm's optimal employment choice to the wage.

\subsection{Bargaining}

In this section we describe the wage bargaining, allowing us to generate wage curves and complete the description of labor demand. We focus on individual bargaining, based on Stole and Zwiebel (1996). The key assumption of the Stole and Zwiebel (1996) individual bargaining framework used here is that firms engage in pairwise negotiations with workers. When a worker joins the firm, wages are renegotiated individually with all workers. Hence, each worker is treated as the marginal worker and the firm is essential in the bargaining process. By its very nature, individual bargaining involves bargaining over wages only.

We believe that this is the appropriate bargaining setup for our model for two reasons. First, on theoretical grounds, Stole and Zwiebel (1996) show that individual bargaining may be understood as a Binmore-Rubinstein-Wolinsky (1986) alternating offer game, ensuring that the Nash-bargaining is fully microfounded. Hence the wage curve (20) can be obtained either by fully modeling the pairwise bargaining structure, or by solving a standard generalized Nash bargaining problem ${ }^{8}$. In this sense, individual bargaining is the natural extension of the Mortensen-Pissarides

\footnotetext{
${ }^{8}$ We know from e.g. Gul (1987) that symmetric Nash products can be used to compute the Shapley value. Following footnote 18 of Stole and Zwiebel (1996) but using a generalized sharing rule (with weight $\beta$ for workers and $(1-\beta)$ for firms), it is straightforward to derive a wage curve equivalent to our equation (16).
} 
framework to multi-worker firms, since it allows us to derive the wage curve by solving the Nash bargaining problem. Secondly, we later calibrate to US labor markets, which are better characterized by individual than by collective bargaining. ${ }^{9}$

\subsubsection{Individual Bargaining Solution}

Under individual bargaining, the firm's outside option is not remaining idle, but rather producing with one worker less. The crucial point of the individual bargaining framework is that each worker is treated as the marginal worker. This can be implemented in two ways: either by defining firm's surplus to be $V^{J}\left(H_{i}\right)-V^{J}\left(H_{i}-1\right)$ or by taking the derivative of $V^{J}$ with respect to $H_{i}$ and considering this to be the contribution of the marginal worker. Following Cahuc and Wasmer (2001) we will use the latter approach, so that the multi-worker firm's bargaining problem becomes:

$$
\max _{w} \beta \ln \left(V^{E}-V^{U}\right)+(1-\beta) \ln \frac{\partial V^{J}}{\partial H_{i}}
$$

To obtain an expression for firm's surplus, take the envelope condition of the firm's problem (9), and recall that the first order condition (14) implies that $\frac{\partial V^{J}}{\partial H_{i}}$ be constant over time. This leads to:

$$
\frac{\partial V^{J}}{\partial H_{i}}=\frac{1}{r+\chi}\left(\frac{\xi_{i}-1}{\xi_{i}} A_{i} P_{i}\left(H_{i}\right)-\frac{\partial w}{\partial H_{i}} H_{i}-w\left(H_{i}\right)\right) .
$$

The worker's surplus is standard:

$$
V^{E}-V^{U}=\frac{w\left(H_{i}\right)-r V^{U}}{r+\chi} .
$$

Substituting the expressions for worker's and firm's surplus (17) and (18) into the first order condition of (16) leads to a first-order linear differential equation in the wage

$$
w\left(H_{i}\right)=(1-\beta) r V^{U}+\frac{\xi_{i}-1}{\xi_{i}} \beta P_{i}\left(H_{i}\right) A-\beta H_{i} \frac{\partial w}{\partial H_{i}} .
$$

It is straightforward to confirm that (19) has solution:

$$
\frac{w\left(H_{i}\right)}{P}=r V^{U}+\beta\left(\frac{\xi_{i}-1}{\xi_{i}-\beta} A \frac{P_{i}\left(H_{i}\right)}{P}-r V^{U}\right) .
$$

Equation (20) is the wage curve under individual bargaining.

\subsubsection{Hiring Externality}

The individual bargaining solution presented above displays a hiring externality of the type first explored in partial equilibrium by Stole and Zwiebel (1996a). To see this, note that the wage curve (20) is downward sloping: as the number of workers per firm increases, the bargained wage declines. Formally:

$$
\frac{\partial w}{\partial H_{i}} \frac{H_{i}}{P}=-A \frac{\beta}{\xi_{i}}\left(\frac{\xi_{i}-1}{\xi_{i}-\beta}\right) \frac{P_{i}}{P}<0 .
$$

\footnotetext{
${ }^{9}$ In a companion paper, we compare our results to those derived under a collective bargaining framework, and show that collective bargaining strengthens the impact of product market competition on unemployment and wages substantially.
} 
The reason is shrinking marginal revenue product $[\mathrm{MRP}]$ in conjunction with individual bargaining. To gain intuition, note that the wage takes the standard form of the worker's reservation utility plus a share $\beta$ of the total match surplus. Since each worker is treated as the marginal worker, total match surplus depends on the worker's MRP, as captured by the term $\frac{\xi_{i}-1}{\xi_{i}-\beta} A \frac{P_{i}\left(H_{i}\right)}{P}$. Monopoly power ensures that the MRP is decreasing, so that increasing employment/production reduces the wage. Since all workers are treated as the marginal worker, hiring an additional worker reduces the wage for all workers by $\left|\frac{\partial w}{\partial H_{i}}\right|$. This hiring externality gives firms an incentive to hire more than the socially optimal number of workers, ${ }^{10}$ analogous to the overhiring results in Stole and Zwiebel (1996a) and Smith (1999). In Smith (1999) and Stole and Zwiebel (1996a), however, the source of decreasing MRP is not monopoly power but decreasing returns to scale in production.

Importantly, the hiring externality is intimately linked to the degree of product market competition. First, note that the hiring externality disappears in the perfect competition limit [as $\xi \rightarrow \infty$ ]. This is in line with the results of Cahuc and Wasmer (2001), who show that the hiring externality is absent in a model where constant returns to scale and perfect competition lead to constant MRP. Furthermore, in our setting it is straightforward to show that the hiring externality is stronger when monopoly power is greater. ${ }^{11}$ The intuition is that lower levels of competition are associated with more steeply decreasing MRP, so that wages decline more sharply when firm employment increases at low levels of competition. Hence, the hiring externality works to dampen the negative first order effects of monopoly power on employment.

The magnitude of the hiring externality is also increasing in worker's bargaining power $\beta$. This is intuitive, since the on average higher wages which accompany greater worker bargaining power give the firm an added incentive to depress wages.

\section{Equilibrium}

We proceed to find equilibrium in three steps. First, we focus on firm-level behavior, by identifying the firm's optimal employment-wage pair when it takes aggregate variables as given. Then, we go on to find the quantities and prices which are consistent with market clearing. This will allow us to obtain expressions for all equilibrium variables as functions of the exogenous degree of competition - or equivalently as functions of the number of firms per industry. We call this second stage short-run general equilibrium, since it treats the number of firms as given. In the last step, we will introduce entry costs, which will serve to endogenize the number of firms per industry. This last equilibrium will be referred to as long-run general equilibrium.

\footnotetext{
${ }^{10}$ Whether this hiring externality translates into overhiring will be examined in our section 5 on social efficiency. Also note that under individual bargaining, it is natural to assume that it is the firm which controls firm size.

${ }^{11}$ Formally, this amounts to showing that $\frac{\partial\left|\frac{\partial w}{\partial H_{i}}\right|}{\partial \xi}<0$.
} 


\subsection{Firm-Level Equilibrium}

First, we focus on the firm's optimal choices, taking aggregate variables as given. We already have the wage curve (20), which was derived from the individual wage bargaining. An expression for labor demand may be obtained by substituting (21) into the implicit labor demand equation (15), yielding:

$$
\frac{w\left(H_{i}\right)}{P}=A \frac{P_{i}\left(H_{i}\right)}{P}\left[\frac{\xi_{i}-1}{\xi_{i}-\beta}\right]-\frac{\Phi_{V}}{q(\theta)}\left[\frac{r+\chi}{1-\delta}\right] .
$$

Equation (22) can also be interpreted as a job creation condition. As expected, it is downward sloping, both in the amount of labor demanded $H_{i}$ and in labor market tightness $\theta$.

\section{DEFINITION 1 Firm-Level Equilibrium}

A firm-level equilibrium is defined as a pair of real wages and firm-level employment $H_{i}$ which satisfies both labor demand (22) and the individual bargaining wage curve (20), taking $\left(\theta, \xi_{i}, n_{i}\right)$ as given.

Figure 1 illustrates the firm-level equilibrium graphically in the wage-employment space. Formally, optimal employment for firm $i$ may be computed implicitly as the intersection of the job creation condition (22) and the wage curve (20):

$$
\frac{P_{i}\left(\theta, \xi_{i}\right)}{P}=\frac{\xi_{i}-\beta}{\xi_{i}-1}\left[\left(\frac{r V^{U}}{P}+\frac{1}{1-\beta} \frac{\Phi_{V}}{q(\theta)}\left(\frac{r+\chi}{1-\delta}\right)\right) \frac{1}{A}\right] .
$$

The firm-level equilibrium real wage can be found by substituting (23) back into the job creation condition (22), and then using the flow values of employment (1) and unemployment (2) to substitute out for $r V^{U}$, resulting in:

$$
\begin{gathered}
\frac{w(\theta)}{P}=b+\frac{\beta}{1-\beta} \frac{\Phi_{V}}{q(\theta)}\left[\frac{r+\chi+\theta q(\theta)}{1-\delta}\right], \\
\frac{r V^{U}}{P}=b+\frac{\beta}{1-\beta} \frac{\theta \Phi_{V}}{1-\delta} .
\end{gathered}
$$

Note that although wages do not depend explicitly on demand elasticity $\xi_{i}$, they will depend on competition indirectly, via equilibrium labor market tightness $\theta$.

We can also compute the firm's optimal employment explicitly by combining the firm-level equilibrium condition (23) with the demand curve facing firm $i$ (10) and with the reservation wage (25). Additionally imposing symmetric Cournot equilibrium within each industry gives

$$
H_{i}\left(\theta \mid I, \xi_{i}\right)=\left[\left(\frac{\xi_{i}-\beta}{\xi_{i}-1}\right)\left(b+\frac{\beta}{1-\beta} \frac{\theta \Phi_{V}}{1-\delta}+\frac{1}{1-\beta} \frac{\Phi_{V}}{q(\theta)} \frac{r+\chi}{1-\delta}\right)\right]^{-\sigma} A^{\sigma-1} \frac{I}{n_{i}} .
$$

Firm-level real profits can now be computed as the difference between revenues on the one hand, and labor and vacancy costs on the other:

$$
\frac{\pi_{i}\left(\theta \mid I, \xi_{i}\right)}{P}=A \frac{P_{i}\left(\theta, \xi_{i}\right)}{P} H_{i}\left(\theta \mid I, \xi_{i}\right)-\frac{w(\theta)}{P} H_{i}\left(\theta \mid I, \xi_{i}\right)-\Phi_{V} v_{i}
$$

where $v_{i}$ is the steady-state level of vacancies created by incumbent firms and is given by $\frac{\tilde{\chi} H_{i}\left(\theta \mid I, \xi_{i}\right)}{q(\theta)}$. 


\subsection{Short Run General Equilibrium}

Now, we determine the 'short-run' general equilibrium, taking as given the number of firms $n_{i}$ in each industry. In our setting, this is equivalent to pinning down all equilibrium variables as functions of the degree of competition $\xi_{i}$. This will allow us to determine the impact of increasing competition on equilibrium unemployment and wages.

DEFINITION 2 Short-run General Equilibrium

A short-run general equilibrium is defined for given $\left(\xi_{i}, n_{i}\right)$ and parameters $\left(\beta, \sigma, b, \Phi_{V}, \delta, \chi, r, A\right)$ as a value of $\theta$ which:

(i) is a firm-level equilibrium satisfying (23)-(25)

(ii) is a symmetric Cournot equilibrium in each industry satisfying (26) and $\xi_{i}=n_{i} \sigma$ for all $i$

(iii) satisfies the following aggregate resource constraint

$$
I=\int\left[\frac{w(\theta)}{P} H_{i}\left(\theta \mid I, \xi_{i}\right)+\frac{\pi_{i}(\theta)}{P} H_{i}\left(\theta \mid I, \xi_{i}\right)+\Phi_{V} v_{i}\right] n_{i} d f(i)
$$

where $f(i)$ is the distribution of industries.

12

When all industries $i$ are identical and are distributed uniformly over the unit interval we obtain a simpler version of the aggregate resource constraint:

$$
I=\left[\frac{w(\theta)}{P} H_{i}\left(\theta \mid I, \xi_{i}\right)+\frac{\pi_{i}\left(\theta \mid I, \xi_{i}\right)}{P} H_{i}\left(\theta \mid I, \xi_{i}\right)+\Phi_{V} v_{i}\right] n_{i}
$$

Substituting in from (24), (26), (23) and (27) leads immediately to the short-run equilibrium condition

$$
A=\frac{\xi-\beta}{\xi-1}\left(b+\frac{\beta}{1-\beta} \frac{\theta \Phi_{V}}{1-\delta}+\frac{1}{1-\beta} \frac{\Phi_{V}}{q(\theta)}\left(\frac{r+\chi}{1-\delta}\right)\right) .
$$

The short-run general equilibrium condition (30) is monotonically increasing in $\theta$, so that existence of equilibrium is guaranteed if

$$
A>\frac{\xi-\beta}{\xi-1} b
$$

When the economy approaches full competition [as $\xi \rightarrow \infty$, (31) reduces to the standard condition $A>b$ that workers' productivity be greater in employment than in unemployment.

Equation (30) is key, since it relates the degree of competition $\xi$ to short-run equilibrium labor market tightness $\theta$. Once we have $\theta(\xi)$, we can obtain the equilibrium unemployment rate from the Beveridge curve:

$$
u(\xi)=\frac{\chi}{\chi+\theta(\xi) q[\theta(\xi)]}
$$

The remainder of equilibrium variables are found as follows: Given the total number of agents in the economy $N$, we can find equilibrium aggregate employment as $n_{i} H_{i}(\xi)=N[1-u(\xi)]$. We will find it convenient to normalize

\footnotetext{
${ }^{12}$ Note that it is not necessary to take the measure $\delta$ of pre-entry firms into account in aggregate income. They do not yet produce and only incur vacancy costs $\Phi_{V} \widetilde{v}_{i}$, where $\widetilde{v}_{i}=\frac{H_{i}}{q(\theta)}$ are sufficient to reach the firm's steady-state employment level at the start of the next period. Hence the firm's profits and vacancy costs sum to zero.
} 
$N=1$. With $H(\xi)$ in hand, we can find aggregate output and subsequently the equilibrium quantity of good $i$, and of course short-run equilibrium employment per firm $H_{i}(\xi)$ and price $P_{i}(\xi)$, all in terms of the given degree of competition.

\subsubsection{An Equivalence Result}

Equation (30) makes it clear that equilibrium $\theta$ depends only upon the demand elasticity facing the firm $\xi$, and not on either of its components $n$ or $\sigma$ independently. This implies that it is equivalent to vary competition by varying the number of firms per industry [as we do here] or by varying the elasticity of substitution among goods $\sigma$ as in Blanchard and Giavazzi (2003). This equivalence result depends on the way in which vacancy costs are treated in aggregate income. Here, we include vacancy posting costs in aggregate income, thereby implicitly assuming that vacancy posting costs are not 'thrown out the window', but are rather paid in return for services like advertising. ${ }^{13}$ When vacancy posting costs are netted out of aggregate income, a somewhat less tractable equilibrium condition emerges:

$$
\begin{aligned}
A= & \left\{\frac{\xi-\beta}{\xi-1}\left[b+\frac{\Phi_{V}}{q(\theta)} \frac{\beta \theta q(\theta)+r+\chi}{(1-\beta)(1-\delta)}\right]\right\} \\
& -\frac{\chi \Phi_{V}}{q(\theta)}\left\{\frac{\xi-\beta}{\xi-1}\left[b+\frac{\Phi_{V}}{q(\theta)} \frac{\beta \theta q(\theta)+r+\chi}{(1-\beta)(1-\delta)}\right]\right\}^{\frac{\sigma}{\sigma-1}} .
\end{aligned}
$$

In this case, $\sigma$ does play an independent role, and hence varying $n$ and $\sigma$ is no longer equivalent ${ }^{14}$.

\subsubsection{Comparative Statics I: Varying Competition}

The characterization of short-term equilibrium allows us to examine the qualitative impact of varying the degree of competition $\xi$ on short-term equilibrium unemployment and wages. It is straightforward to check that increasing our measure of competition $\xi$ will lead to decreased equilibrium unemployment and to increased equilibrium wages. These and other comparative static results for short-term equilibrium are summarized in Lemma 1 and Proposition 1. All proofs are found in the Appendix.

LEMMA 1 Short-run equilibrium labor market tightness is a strictly increasing function of firm-level demand elasticity $\xi$.

PROPOSITION 1 In short-run equilibrium:

(i) unemployment is strictly decreasing in competition $\xi$,

(ii) wages are strictly increasing in competition $\xi$.

\footnotetext{
${ }^{13}$ It is straightforward to show that aggregate income $I$ is decreasing in $\Phi_{V}$, so that it is not possible to inflate aggregate income by increasing vacancy costs.

${ }^{14}$ Quantitatively, the two methods of aggregation yield nearly indistinguishable results when competition is varied via the number of firms per industry. Details are available from the authors.
} 
We identify two main channels by which an increase in competition affects employment and unemployment: (1) the output-expansion channel (2) the hiring externality channel. Via the first channel, increased competition leads to increased employment and decreased unemployment, while the second channel works in the opposite direction.

We first focus on the output-expansion channel, which was also identified by Blanchard and Giavazzi (2003). From equation (23), higher demand elasticity leads to a lower equilibrium price. From (10), industry-level output will clearly grow in response to lower equilibrium prices. This is the output expansion effect of greater competition, which also leads to greater industry-level employment via the linear production function. Since steady-state vacancies are directly related to employment as $v_{i}+\delta \widetilde{v}_{i}=\frac{\widetilde{\chi} H_{i}}{q(\theta)}+\delta \frac{H_{i}}{q(\theta)},{ }^{15}$ an increase in equilibrium employment leads to an increase in equilibrium vacancies, and hence to an increase in labor market tightness $\theta$, and a decrease in unemployment via the Beveridge curve.

The second channel is related to the properties of individual bargaining over wages. Under individual bargaining, firms facing imperfectly elastic demand have an incentive to overhire, as described in the previous section. As competition increases, the hiring externality is diminished, placing downward pressure on vacancies and employment. The results of Proposition 1 indicate that the first channel prevails, so that the net effect of competition on steady-state employment is indeed positive. However, to what extent the hiring externalities are able to mitigate the detrimental effects of monopoly power on equilibrium unemployment is a quantitative question, one which we address in the following section.

Interestingly, Proposition 1 also shows that the equilibrium wage turns out to be increasing in competition. This conclusion is the opposite of that drawn by the recent literature on wages and the sharing of monopoly rents (e.g. van Reenen, 1996). The source of the disparity is that the rent-sharing papers typically look at only one isolated industry, while we consider broader increases in competition which affect all industries at once. The general equilibrium effect of greater competition is to increase vacancies and tightness in all sectors, making it easier for unemployed workers to find new jobs. This increases the value of the worker's outside option, thereby improving the worker's bargaining position and increasing his/her wage, as illustrated by equation (25) in conjunction with Lemma 1. This is similar to the positive wage effect of competition found by Blanchard and Giavazzi (2003). It is also consistent with data on labor shares (simply computed as employee compensation over GDP) and entry regulation, as illustrated in Figure 3.

\subsubsection{Comparative Statics II: Varying Parameters}

Proposition 2 summarizes short-run equilibrium comparative statics.

PROPOSITION 2 Effects of parameters on equilibrium $\theta$ and unemployment

In short-run equilibrium:

(i) labor market tightness $\theta$ is decreasing in the parameters $b, \Phi_{V}, r, \delta$, and $\tilde{\chi}$;

(ii) unemployment is increasing in the parameters $b, \Phi_{V}, r, \delta$ and $\tilde{\chi}$;

\footnotetext{
${ }^{15}$ Recall that steady state vacancies are derived from two sources: incumbent and entrant firms. Incumbent firms create $v_{i}=\frac{\widetilde{\chi} H_{i}}{q(\theta)}$ vacancies, while the $\delta$ pre-entry firms create $\widetilde{v}_{i}=\frac{H_{i}}{q(\theta)}$ vacancies. That is, incumbent firms replace the fraction $\widetilde{\chi}$ of workers from which they expect to be separated, while entrants must create enough vacancies to hire their entire desired workforce.
} 
(iii) labor market tightness $\theta$ is decreasing in $\beta$ and unemployment is increasing in $\beta$ if either $b<\frac{\Phi_{V}}{1-\delta} \theta$ or $b \geq \frac{\Phi_{V}}{1-\delta} \theta$ and $\xi \geq \widetilde{\xi}$ where $\widetilde{\xi}=\frac{b(1-\beta)^{2}+\frac{\Phi_{V}}{1-\delta} \theta[\beta+\beta(1-\beta)]+\frac{\Phi_{V}}{q(\theta)} \frac{r+\chi}{1-\delta}}{\frac{\Phi_{V}}{q(\theta)} \frac{r+\chi}{1-\delta}+\frac{\Phi_{V}}{1-\delta} \theta}$.

The results of parts (i) and (ii) of Proposition 2 are standard for search and matching models. Part (iii) merits comment. Unemployment's reaction to an increase in workers' bargaining power is standard, unless the degree of competition is very low. The intuition is that higher workers' bargaining power strengthens the overhiring effect, in the sense that $\frac{\partial^{2} w}{\partial H_{i} \partial \beta}<0$ for given $H_{i}$ and $P_{i}$. At very low levels of competition, the overhiring effect discussed in section 2.4 is particularly strong. In this case, increasing bargaining power strengthens the overhiring effect so much [i.e. increasing firms' incentives to hire more workers to depress wages], that the end result is lower unemployment.

\subsection{Long-run General Equilibrium}

Now we are ready to endogenize the degree of competition, or equivalently, the number of firms in each industry. In the long-run, firms may enter each industry by paying a real entry cost $\Phi_{E}$. Entry by firms will continue until profits net of entry costs within each industry have been competed down to zero. Hence, free entry in the presence of barriers to entry leads to equilibrium industry size $n^{*}$, which is defined implicitly by:

$$
\frac{r+\delta}{1+r} \Phi_{E}=\frac{\pi_{i}\left(n^{*}\right)}{P}
$$

where the firm's equilibrium profits per period are given by (27). The free entry condition (33) states that the entry cost must be amortized by profits over the firm's expected lifespan. The greater is the firm's exit probability $\delta$, the higher must be the equilibrium profits to amortize a given level of entry costs. Since equilibrium profits are decreasing in competition, free entry forges a negative link between barriers to entry and the number of firms.

Entry barriers may take two complementary forms, time and pecuniary costs. Both the data on entry costs collected by Logotech, S.A. for the OECD (as reported in Fonseca, et. al. (2001)) and that of Djankov, et. al. (2002) report the time it takes to satisfy all regulatory entry requirements. In addition, Djankov, et. al. (2002) present data on the official fees which must be paid in order to obtain all licenses and permits, as a percentage of annual per capita GDP.

We combine the fee and regulatory delay measures to obtain a single quantification of barriers to entry. We convert the regulatory delay (measured in months) into a pecuniary opportunity cost consisting of lost profits during the setupperiod, plus the wages of one worker who is charged with setting up the firm. This implies that a day of waiting is more costly in a high-profit and/or high-wage economy. Formally, total barriers to entry are found as:

$$
\Phi_{E}(n)=\left[d\left(\frac{\pi}{P}(n)+\frac{w}{P}(n)\right)\right]+f \cdot I(n) .
$$

where $d$ is the regulatory delay and $f$ are entry fees as a share of aggregate monthly income. Combining (34) with the free entry condition (33) yields:

$$
\frac{r+\delta}{1+r}\left[d\left(\frac{\pi}{P}\left(n^{*}\right)+\frac{w}{P}\left(n^{*}\right)\right)+f \cdot I\left(n^{*}\right)\right]=\frac{\pi}{P}\left(n^{*}\right) .
$$

Equation (35) closes the long-run equilibrium. It implicitly determines the endogenous long-run industry size $n^{*}$, or equivalently, it determines the endogenous degree of competition $\xi^{*}=\sigma n^{*}$ in long-run equilibrium. As long as 
$d<\frac{1+r}{r+\delta}$, as is the case in all the data reported in Table 1, equation (35) defines a negative relationship between barriers to entry and the degree of competition in long-run equilibrium. Hence, an increase in entry barriers of either form leads to a long-run equilibrium decrease in industry size $n^{*}$ or equivalently, to a decrease in the demand elasticity faced by firms $\xi^{*}$.

\section{Quantitative Results}

We are now in a position to calibrate our model and approach our quantitative questions. We first explain in detail how we calibrate the basic model to match a set of labor market data from the United States. Then, for this calibration we ask: What is the impact of increasing competition on equilibrium unemployment and wages? That is, we examine by how much unemployment decreases and by how much wages increase due to an increase in our measure of competition [demand elasticity $\xi$ ]. Next, we run two policy experiments, each of which is designed to gauge the relative importance of entry costs and unemployment benefits in accounting for the difference in U.S. and continental European unemployment rates.

\subsection{Calibration}

One model period is one month. All parameters are reported in Table 2. We use estimates from the literature to guide our choices for the first group of parameters. The bargaining power of workers, $\beta$, has recently been estimated between 20\%, (Cahuc, Gianella, Goux and Zylberberg, 2002) and 50\% (Abowd and Allain, 1996, Yashiv, 2001). Petrongolo and Pissarides (2001) report $\eta$, the elasticity of the matching function with respect to unemployment, to be in the range of [0.4;0.7]. We set $\beta=\eta=0.5$, thus choosing standard values and imposing the Hosios (1990) condition. ${ }^{16}$ For simplicity, we normalize the level of technology $A$ to unity. Our choice for the annualized real interest rate $r=0.04$ is standard. Unemployment benefits in the U.S. replace $50 \%$ of the past income for half a year, so we choose $b$ to be 0.274 , which is roughly consistent with a replacement rate ${ }^{17}$ of $30 \%$. In our setting, the choice of the elasticity of substitution among goods $\sigma$ has no impact on the endogenously determined elasticity of substitution facing individual firms $\xi$. Since $\xi=n \sigma$, our choice of $\sigma$ only serves to normalize the equilibrium number of firms per industry. We take $\sigma=2$.

We choose the remaining parameters to match some stylized labor market data for the U.S. during the period 1989-2002. Specifically, we replicate an unemployment rate of 5.53\%, an average duration of unemployment of 3.8 months (corresponding to a worker's matching rate of $\theta q(\theta)=0.26$ ), and an adjusted ${ }^{18}$ vacancy/unemployment ratio $^{2}$ of 0.3. The latter figure is consistent with the JOLTS database, where the average of the vacancy/unemployment ratio

\footnotetext{
${ }^{16}$ In section 5 we show that the Hosios condition is necessary but not sufficient for social efficiency in our setup. Our result augments that of Smith (1999). While Smith (1999) requires constant returns to labor for efficiency, what matters here is a constant marginal revenue product of labor.

${ }^{17}$ Rather than introducing heterogeneity among unemployed by cutting off their benefits, we prefer to adjust the generosity of unemployment compensation. This is standard, as is the choice of a 30\% replacement ratio for the United States (see e.g. Ljungqvist and Sargent (1998)).

${ }^{18}$ The terminology of our model is somewhat misleading. What is called a vacancy in the model is not directly comparable to a vacancy in the data because firms post as many vacancies so as to hire in expectation the desired number of workers. Therefore we adjust the vacancies coming
} 
for the period ${ }^{19}$ beginning $1 / 2002$ is one third. The exogenous total separation rate $\chi=0.0154$, is pinned down by the Beveridge curve in conjunction with our values for unemployment and unemployment duration. We set $\delta=0.01$, so that the monthly probability that a firm will cease to exist is in line with the one and five year firm survival probabilities reported in Dunne, Roberts and Samuelson (1988), Mata and Portugal (1994) and Wagner (1994). Finally, the scaling parameter of the matching function $s$ must satisfy $s=\frac{0.26}{\theta^{1-\eta}}$.

We are left with a long-run equilibrium condition (35) which relates vacancy posting costs $\Phi_{V}$ to firm's demand elasticity $\xi$. We close the model by choosing a value for $\Phi_{V}$. We choose that level of vacancy posting costs which leads to a long-term U.S. equilibrium unemployment rate of $5.53 \%$. This leads to a value of $\Phi_{V}=0.573$, so that hiring costs per worker are $q(\theta) \Phi_{V}=2.41$ units of output, which corresponds to about $21 \%$ of annual payroll. This is consistent with Hamermesh and Pfann (1996), who report fixed hiring costs in the range of $20 \%$ to $100 \%$ of annual payroll expenses for a worker.

Finally, we also calibrate a balanced budget version of the model in which unemployment benefits are financed by equal magnitude income and payroll taxes $\left(\tau_{I}, \tau_{P}\right)$. The only parameter affected is equilibrium vacancy posting costs $\Phi_{V}$, which falls slightly to 0.547 . In the US model economy, income and payroll taxes of less than $1 \%$ are necessary to finance unemployment benefits.

\subsection{A little bit of competition goes a long way}

Figure 2 shows how equilibrium labor market variables react as the degree of competition is varied exogenously in the calibrated model. The quantitative message is clear: A little bit of competition goes a long way. The main benefits to competition for employment and wages are due to the transition between monopoly and oligopoly, not to the transition from oligopoly to perfect competition. The top left hand panel of Figure 2 plots the equilibrium unemployment rate $u$ against the number ${ }^{20}$ of firms per industry, our measure of competition. The decrease in unemployment can be attributed [via the Beveridge curve] to the increase in labor market tightness depicted in the upper right panel of Figure 2.

However, the total impact of competition on unemployment is surprisingly modest. By increasing the number of firms per industry from one to five, equilibrium unemployment falls by less than two percentage points, from $7.62 \%$ to about $5.69 \%$. Put another way, even if all continental European industries were monopolies, while all US industries were perfectly competitive, the model would only predict a difference of slightly more than two percentage points of unemployment, less than half the actual gap of about 3.95\% over the period 1989-2002.

The impact of competition on short-run equilibrium wages and profits is considerably stronger. The middle panels out of our model by the matching rate for firms before comparing it to the data. Let $\theta_{d}$ denote the data, then we have the relationship:

$$
\theta_{d}=\theta \frac{1}{q(\theta)}=\frac{1}{s} \theta^{1+\eta} .
$$

\footnotetext{
${ }^{19}$ The JOLTS database only offers vacancy data starting 12/2000.

${ }^{20}$ Recall that the number of firms is the result of a normalization via $\sigma$. The more meaningful - but perhaps less intuitive - measure of product market competition is the demand elasticity $\xi$ faced by each individual firm. In all of our calibrations, $\xi=n \sigma$ and $\sigma=2.0$, so doubling the number of firms gives the demand elasticity.
} 
of Figure 2 show that equilibrium wages increase by about $50 \%$ when the number of firms is increased from 1 to 5 , while per-firm equilibrium profits drop to about 1/10th of their monopoly levels. That wages are increasing despite shrinking profits may seem surprising initially. It is useful to recall, however, that the equilibrium wage is the sum of two components: a share $\beta$ of match surplus and the value of the worker's outside option. Greater competition leads to higher equilibrium labor market tightness, so that unemployed workers find it easier to find a new job, raising the equilibrium value of unemployment - or equivalently the worker's outside option - which leads to an increase in the reservation wage. Although equilibrium match surplus increases slightly as well [in equilibrium the marginal worker must become more valuable as $\theta$ increases, because it is more costly to search for him/her], it is the improvement in the worker's bargaining position which accounts for the vast majority of the increase in wages due to competition.

\subsection{Income Taxes}

In order to run policy experiments, we must also take into account that unemployment benefits must generally be financed by taxes. We impose equal magnitude income and payroll taxes, which are just large enough to finance the equilibrium expenditures on unemployment benefits:

$$
\left[\tau_{I}+\tau_{P}\right] \frac{w}{P}[1-u]=b u
$$

It is straightforward to confirm that the short-run equilibrium condition (30) becomes:

$$
A=\frac{\xi-\beta}{\xi-1}\left(\frac{1+\tau_{P}}{1-\tau_{I}} b+\frac{\beta}{1-\beta} \frac{\theta \Phi_{V}}{1-\delta}+\frac{1}{1-\beta} \frac{\Phi_{V}}{q(\theta)} \frac{r+\chi}{1-\delta}\right),
$$

while the entry cost definition must be updated to take payroll taxes into account

$$
\Phi_{E}(n)=\left[d\left(\frac{\pi}{P}(n)+\left(1+\tau_{P}\right) \frac{w}{P}(n)\right)\right]+f \cdot I(n) .
$$

\subsection{A Simple Policy Experiment}

We now use the balanced budget version of the model to run a simple policy experiment, whose goal is to gauge the relative importance of product and labor market institutions in accounting for the US-continental Europe unemployment differential. In particular, differing labor market institutions [LMI] are represented as differing levels of real unemployment benefits $b_{U S}=0.274$ and $b_{\text {Euro }}=0.554$, which correspond to replacement rates of $30 \%$ and $70 \%$ respectively. Differing product market institutions [PMI] are represented as differing entry cost regimes $\left\{d_{\text {Euro }}, f_{\text {Euro }}\right\}$ and $\left\{d_{U S}, f_{U S}\right\} .{ }^{21}$ To decompose the total resulting unemployment differential into PMI and LMI components, we move from the US to the continental European calibration in two steps. Taking the calibration to US data as a starting point, we first increase $b$ so that the replacement rate takes on its continental European value, while maintaining low US entry costs. The difference between the US and hybrid long-run equilibrium unemployment rates $\Delta u_{L M I}$ gives the unemployment differential due to the labor market institution. In the second step, we move from the hybrid to the continental European economy by increasing entry costs to continental European levels. This allows us to

\footnotetext{
${ }^{21}$ Following Fonseca, et. al. (2001) and Pissarides (2001), we use the regulatory delay index based on the Logotech/OECD data, together with Djankov, et. al. (2002)'s cost data.
} 
calculate $\Delta u_{P M I}$, the unemployment differential due to the product market institution. Also of interest will be the share of the total difference in long-run equilibrium unemployment rates which is due to PMI, which we define as share $_{P M I} \equiv \frac{\Delta u_{P M I}}{\Delta u_{P M I}+\Delta u_{L M I}}$.

The long-run equilibrium for the US economy is shown in column [1] of Table 3, while columns [2] and [3] represent the hybrid and continental European long-run equilibria respectively. Product market regulation is only responsible for about $13 \%$ of the US-continental European unemployment differential. In absolute terms, stricter continental European product market regulation is responsible for about $\Delta u_{P M I}=0.42$ percentage points of unemployment, while more generous unemployment benefits are responsible for about $\Delta u_{L M I}=2.79$ percentage points of additional unemployment. ${ }^{22}$ This indicates that although product market deregulation is likely to have some impact on unemployment, labor market reforms would clearly seem to be considerably more effective. The reason can again be traced to the countervailing hiring externality inherent in the individual bargaining setup, which effectively counteracts much of the detrimental impact of monopoly power on unemployment. ${ }^{23}$

\subsection{A Second Policy Experiment: Interactions between $b$ and $\Phi_{E}$}

Inherent in the policy experiment presented above is an ordering of reforms. In the previous subsection, we have chosen to examine the effects of first deregulating continental European product markets, and then reforming labor markets. It is important to note that this maximizes the unemployment-impact of product market reform. At higher levels of unemployment benefits, entry costs have a greater negative impact on employment and wages.

The reason is that there is a pernicious interaction between the level of unemployment benefits and entry costs, as illustrated in Figure 4. Even if a given differential in entry costs results in exactly the same differential in tightness, the impact of that tightness differential on unemployment varies according to $b$. The reason is that higher- $b$ equilibria involve lower levels of labor market tightness. By the Beveridge curve, unemployment reacts more sensitively to a given tightness differential when tightness is low. This is simply due to the constant returns to scale feature of the matching function, which leads to worker's matching rates $\lambda_{w} \equiv \theta q(\theta)$ to display decreasing returns to scale in tightness $\theta$.

To quantify this interaction, we run a second policy experiment. Now, we define the hybrid economy as being that which combines high European-style entry costs with low US replacement rates. As a result, the increase in unemployment due to PMI shrinks even further. This is reflected in the final column of Table 3. When entry costs are varied at low levels of unemployment benefits, the difference in entry barriers can only account for $0.29 \%$ points of unemployment differential, which corresponds to about $9 \%$ of the total US-continental European unemployment differential.

\footnotetext{
${ }^{22}$ These two institutions fall short of explaining the entire gap between US and continental European unemployment rates, which was 3.95 percentage points over the period 1990-2002, according to BLS data. Recall that there are other institutional differences such as firing costs from which we abstract here.

${ }^{23}$ In a companion paper, we show that under collective bargaining, entry barriers can indeed account for a substantially larger portion of the US-continental European unemployment gap.
} 


\subsection{Wage Impact}

We confirm the quantitative relevance of Blanchard and Giavazzi (2003)'s political economy argument. These authors assert that the package of product and labor market reform may be more palatable to workers than labor market reform alone, since the spoonful of sugar of product market reform-induced wage increases would make the bitter medicine of labor market reform easier to swallow ${ }^{24}$. Indeed, in our first policy experiment workers would be compensated for the loss of unemployment benefits with a substantial competition-induced net real wage increase of about $11 \%$, which corresponds to an increase in net real wages from 0.792 to 0.879 . This wage increase holds regardless of whether labor or product market reform is introduced first. Once again, nearly all of the competition-induced wage increase is due to the increase in workers' reservation utility. Greater product market competition leads to higher rates of vacancy creation, increasing labor market tightness and making it easier for unemployed workers to find jobs. This increases the value of workers' outside option of unemployment and renewed job search, improving their bargaining position. Furthermore, Figure 3 illustrates the empirical relevance of product market reform for wages.

\subsection{Robustness}

We now proceed to check the robustness of our quantitative results to our 'free' parameter choices. The only parameters in which we are guided by, but not pinned down by, the data are matching elasticity $\eta$, worker's bargaining power $\beta$ and firm death rate $\delta$. The purpose of this section is to check the robustness of our results to these three semi-free parameters. We find that our choice of these parameter values is innocuous and has only negligible effects on the results that we report.

\subsubsection{Setup}

We take the calibration to the U.S. economy as a starting point and vary the variable of interest (e.g. firm death rate) over a wide range of values (e.g. [0;0.0154], so that for the highest value all breakups are caused by firm-closures). For each of these values we recalibrate the model to still fit our targets of a 5.53\% unemployment rate, 3.8 months unemployment duration, 4.2 months vacancy duration and a replacement rate of 0.30 . The top left panel in figures 5-7 reports how vacancy posting costs, $\Phi_{V}$, and the scaling parameter of the matching function have to be adjusted to meet our calibration targets. The top left panel also shows the effect of this recalibration on the long-run equilibrium demand elasticity that firms face. This recalibration is important, because it allows us to compare results across different parameter values directly.

Based on the recalibrated models we then conduct three regulation experiments. Each experiment is conducted for 30 different values of the variable of interest $(\delta, \eta, \beta)$. Starting from U.S. entry barriers, experiment $\mathrm{D}$ varies the administrative delay from the U.S. level of 7.5 days to 600 days, which is roughly ten times the European entry delay. The results of experiment D are reported in the top right panel of diagrams 5-7. Again starting from the U.S. level of $0.5 \%$ of per capita GDP experiment $\mathrm{F}$ varies the administrative fees up to a level of $200 \%$ of per capita GDP (which

\footnotetext{
${ }^{24}$ A similar result is found by Seldeslachts (2002) in an efficiency wage model and by Peretto (2000) in a growth model.
} 
is roughly 40 times the European level of fees) while keeping the entry delay at its U.S. level of 7.5 days. The results of experiment $\mathrm{F}$ are reported in the bottom left panel of diagrams 5-7. Finally, experiment $\mathrm{M}$ considers multiples of U.S. entry barriers from 1 to 50 . Again this surpasses the data by far. EU delay is about nine times higher than U.S. delay; EU fees are roughly 40 times higher than their U.S. counterparts. The results of experiment $\mathrm{M}$ are reported in the bottom right panel of diagrams $5-7$.

\subsubsection{Results}

When analyzing firm death rate, $\delta$ (figure 5) we realize that no modifications in vacancy posting costs or the scaling parameter are necessary to maintain our calibration targets. This is not surprising as an increase in the firm death rate translates almost one to one in a reduction in the exogenous match-breakup rate. We note, however, that the equilibrium demand elasticity falls substantially as the firm death rate increases. Higher firm death rates imply less time to recoup the entry-cost investment and thus lead to fewer firms in equilibrium - which manifests itself in the falling firm-level demand elasticity. The striking finding is that it is indeed possible to achieve an unemployment rate of more than $8 \%$. However, this is only obtained for a setup where all separations are due to firm-closures and additionally administrative delay is at 600 days, i.e. 10 times its actual European level! For the observed European entry barriers our findings of a negligible effect of entry barriers holds for any possible choice of firm death rates.

Let us next consider the matching elasticity, $\eta$ (figure 6). We analyze variations of $\eta$ in the interval $[0.1 ; 0.9]$ and recall that our chosen value was 0.5. It turns out that the calibration is remarkably insensitive to choices of $\eta$ and small variations in the scaling parameter of the matching functions are sufficient to reestablish compliance with our calibration targets. Very low values of the matching elasticity indeed lead to strong effects of regulation. However, similar to the case of the firm death rate, this effect only kicks in after surpassing European values of entry barriers. The economic intuition behind this finding is quite simple. High matching elasticities imply that worker matching probabilities only change very little ${ }^{25}$ in response to a larger amount of available vacancies that would be brought about by deregulation. In addition, firm matching-probabilities react very sharply. On the other hand, low values of $\eta$ imply that worker matching rates react sharply to an increase in vacancies, which has a direct positive effect on bargained wages and therefore kills off the job-growth process almost immediately. We conclude that it is possible to obtain unemployment rates of up to $8 \%$ if one is willing to assume extremely low matching elasticities of $\eta=0.1$ and an administrative delay 10 times higher than observed in Europe. For any value of entry barriers actually observed in the data unemployment rates barely exceed $6 \%$.

Finally, in graph 7 we consider the robustness of our results to variations in the bargaining power $\beta$ of workers. Lower worker bargaining power requires substantially higher vacancy posting costs to remain at our original calibration targets for the $5.53 \%$ unemployment rate. For $\beta=0.2, \Phi_{V}=1.93$, wages drop considerably and the number of firms increases substantially. Nevertheless, deregulation has the strongest effects for low values of worker bargaining power because this is when the overhiring effect is smallest. However, even for such low bargaining powers the unemployment rate for European level entry costs barely surpasses $6.0 \%$. The highest unemployment rates that can be

\footnotetext{
${ }^{25}$ Recall that the firm matching-probability is given by $\theta^{-\eta}$ and the worker matching-probability by $\theta^{1-\eta}$.
} 
achieved are a maximum of $7 \%$ for entry regulations that either involve delays of 600 days or fees twice as high as per capita GDP.

To sum up, our reported result that increasing the regulation of entry to the U.S. product market to European levels has only negligible employment consequences is consistent with a wide array of choices for our somewhat 'free' parameters and by no means a special case of our model.

\section{Social Efficiency}

We now consider the welfare implications of differing degrees of product market competition under individual bargaining. This allows us to make more precise the countervailing effects of monopoly power on the one hand, and the hiring and search externalities on the other. Any setup where firms take their product market power into account will lead to underprovision of goods, and hence underhiring. At the same time firms in individual bargaining settings have an incentive to overhire and thus overproduce (Stole and Zwiebel, 1996) which may counteract some of the monopoly distortions. Thus, one might see individual bargaining as inducing monopolistically competitive firms to 'self-regulate' and increase output, bringing them closer to the social optimum. ${ }^{26}$ In the following, we compare the monopolistic competition and individual bargaining equilibrium to the social optimum.

The social planner wishes to maximize per capita aggregate consumption, subject to matching frictions. Total output of the economy can simply be written as $A H$ where $H$ is aggregate employment. Furthermore, given that all goods enter the utility function symmetrically, and $H=(1-u)$, per capita consumption of the aggregate good is given by $A(1-u)$. Using our definition of labor market tightness we can write economy wide per-period vacancy posting costs as $\Phi_{V} \theta u$ so that the per period social welfare function becomes $A(1-u)-\Phi_{V} \theta u$.To focus on the monopoly, bargaining and matching distortions, we consider the special case where $b=0$ and $\delta=0$. The central planning problem becomes:

$$
\max _{\left\{u_{t+1}, \theta_{t}\right\}_{t=0}^{\infty}} \sum_{t=0}^{\infty}\left(\frac{1}{1+r}\right)^{t}\left\{A\left(1-u_{t}\right)-\Phi_{V} \theta_{t} u_{t}+\mu_{t}\left[u_{t+1}-u_{t}-\chi\left(1-u_{t}\right)+\theta_{t} q\left(\theta_{t}\right) u_{t}\right]\right\}
$$

where $\mu_{t}$ denotes the shadow value of an extra vacancy. From the first order condition for labor market tightness we obtain

$$
\mu_{t}=\frac{\Phi_{V}}{q\left(\theta_{t}\right)} \frac{1}{1-\eta\left(\theta_{t}\right)} \quad \text { for all } t
$$

where $\eta$ denotes the elasticity of the matching function with respect to $\theta$, i.e. $\eta=-\frac{\theta q^{\prime}(\theta)}{q(\theta)}$.Combining the first order conditions for $\theta_{t}$ and $u_{t+1}$, using the envelope condition and imposing the steady state condition that $\theta_{t}=\theta$ and $u_{t}=u$ we find an expression for constrained Pareto-efficient labor market tightness similar to that in the decentralized economies:

$$
A=\frac{\eta}{1-\eta} \theta \Phi_{V}+\frac{1}{1-\eta} \frac{\Phi_{V}}{q(\theta)}(r+\chi)
$$

By comparing (40) to the equilibrium condition of the monopolistic competition-individual bargaining economy (30), we find two conditions for social efficiency:

\footnotetext{
${ }^{26}$ See also the discussion in Pissarides (2000) pages 198-201.
} 
1. $\beta=\eta$, the standard Hosios condition;

2. $\frac{\xi-\beta}{\xi-1}=1$, which reflects the monopoly distortion (through $\xi$ ) and the overhiring effect (via $\beta$ ). As $\xi \rightarrow \infty$ these distortions disappear.

To examine whether (un)employment is below or above its socially efficient level, we compare the socially efficient equilibrium condition (40) to its monopolistic-competition-individual bargaining counterpart (30). For any finite value of $\xi$, the monopoly and overhiring distortions will exactly cancel one another whenever $\beta=1$. When $\beta<1$, however, the monopoly distortion dominates, leading to a socially sub-optimal equilibrium $\theta$ and higher-than socially optimal unemployment rate in the individual bargaining economy. The intuition is that when workers have all of the bargaining power, wages are very high and the hiring externality strongest. At lower levels of bargaining power, $\beta<1$, the hiring externality is diminished, and the monopoly distortion is able to dominate.

The search friction, as reflected in the Hosios condition, is neutralized whenever $\beta=\eta$. Recalling that the RHS of both the socially efficient equilibrium condition (40) and its individual bargaining counterpart (30) are increasing in $\theta$, $\beta$, and $\eta$, we can infer that for $\eta<\beta$ the search friction causes unemployment to be above its socially efficient level. However, for $\eta>\beta$ the search friction implies a lower-than optimal level of unemployment.

Note that under imperfect competition, both conditions for social optimum will only be satisfied simultaneously if $\beta=\eta=1$, which would involve both a degenerate matching function and giving all bargaining power to the workers. Under perfect competition, the standard Hosios condition becomes necessary and sufficient for social efficiency. ${ }^{27}$.

Our specification of $\beta=\eta<1$ unambiguously leads to inefficiently low employment levels. In this case, the search friction is neutralized, while the net effect of the monopoly and individual bargaining distortions is unemployment which is greater than the socially optimal level. Similarly, whenever $\eta<\beta \leq 1$, both the net effect of the monopoly and individual bargaining distortions and the search friction imply underemployment, leading to an equilibrium level of unemployment which is unambiguously greater than the socially efficient level. However, for $\beta<\eta<1$, the search friction implies overemployment whereas the monopoly distortion still suggests underemployment. Given that the two distortions work in opposite directions, it is not clear in this last case whether the level of unemployment will be too low or too high in the decentralized equilibrium as compared to the socially efficient outcome.

Our social efficiency analysis allows us to contribute to the recent debate on the robustness of Stole and Zwiebel (1996a)'s overhiring results. Although we find clear evidence of a hiring externality from (21), we also find that the net effect of the intertwined monopoly distortion and hiring externality is underhiring. There is, however, a further, wagebased definition of overhiring, as noted by Stole and Zwiebel (2003): firms engage in overhiring when workers' wages are lower than their internal marginal (revenue) product to the firm. That is, a worker who would not be hired based on his contribution to marginal output alone is hired due to his contribution to depressing wages. In our setting, this definition of overhiring is satisfied whenever $\frac{\xi-1}{\xi} A P_{i}\left(H_{i}\right)<w\left(H_{i}\right) .{ }^{28}$ From equations (23) and (24), wage-based

\footnotetext{
${ }^{27}$ Our findings are consistent with Smith (1999), who studies social efficiency for the case of perfect competition and decreasing returns to scale, and Cahuc and Wasmer (2001) who study perfect competition and constant returns to scale.

${ }^{28}$ One could also use the somewhat weaker criterion that the worker's marginal revenue product net of hiring costs must be smaller than the wage.
} 
overhiring occurs whenever:

$$
\xi<\beta\left[b \frac{q(\theta)}{\Phi_{v}} \frac{1-\delta}{r+\chi}+\frac{\beta}{1-\beta} \frac{\theta q(\theta)}{r+\chi}+\frac{1}{1-\beta}\right]
$$

In our baseline US calibration, this condition is satisfied whenever $\xi<353.1$, a very broad range indeed. In general, lower levels of competition and higher values of worker's bargaining power $\beta$ will tend to favor the wage-based overhiring criterion.

\section{Conclusions}

The main objective of this paper has been to study the relationship between product market regulation and labor market outcomes. Our main contribution is twofold. First, we develop a dynamic model with imperfect competition and search frictions, which is not only well suited for the quantitative analysis of the present paper but also for studies of interactions between competition and the choice of bargaining regime (Ebell and Haefke, 2003) or interactions of regional labor market institutions and monetary policy (Faia and Haefke, 2003). Our model contains the interesting feature that the standard monopoly distortion of underproduction is partially offset by an overhiring incentive, especially when monopoly power is high.

We then use our model to answer two quantitative questions: (1) What is the impact of increasing product-market competition on equilibrium employment and wages? and (2) What proportion of the US-continental European unemployment difference can be accounted for by differences in entry barriers. We find that it is the transition from monopoly to a few firms per sector that has a larger impact on unemployment rates, hence a little competition goes a long way. When we expose a calibrated United States economy to European entry costs we observe an increase in the unemployment rate of about half a percentage point or slightly more than $10 \%$ of the unemployment rate differential between the U.S. and Europe. Thus, while our qualitative finding that product market deregulation has positive repercussions on labor market outcomes is in accordance with the previous literature, we are the first to quantify the effect of deregulation in a fully microfounded dynamic model and conclude that this effect is substantially smaller than conjectured by previous authors.

\footnotetext{
This would amount to:$$
\frac{\xi-1}{\xi} A \frac{P_{i}\left(H_{i}\right)}{P}-\frac{\Phi_{V} \chi}{q(\theta)}<\frac{w\left(H_{i}\right)}{P}
$$

and would lead to a slightly higher upper bound on $\xi$.
} 


\section{References}

[1] Abowd, J.A. and L. Allain (1996), "Compensation Structure and Product Market Competition," Annales d'Economie et de Statistique, (41/42), 207-218.

[2] Bertrand, M. and F. Kramarz (2002), "Does Entry Regulation Hinder Job Creation? Evidence from the French Retail Industry," Quarterly Journal of Economics 117, 1369-1413.

[3] Binmore, K., A. Rubinstein and A. Wolinsky (1986), “The Nash Bargaining Solution in Economic Modeling," RAND Journal of Economics 17, 176-188.

[4] Blanchard, O. and F. Giavazzi (2003), "Marcoeconomic Effects of Regulation and Deregulation in Goods and Labor Markets," Quarterly Journal of Economics 118, 879-907.

[5] Boeri, T., G. Nicoletti and S. Scarpetta (2000), ”Regulation and Labour Market Performance,” CEPR Discussion paper 2420 .

[6] Bresnahan, T.F. and P.C. Reiss "Entry and Competition in Concentrated Markets," The Journal of Political Economy 99, 977-1009.

[7] Cahuc, P. and E. Wasmer (2001), "Does Intrafirm Bargaining Matter in the Large Firm's Matching Model?" Macroeconomic Dynamics 5, 178-89.

[8] Cahuc, P., C. Gianella, D. Goux, and A. Zylberberg (2002), "Equalizing Wage Differences and Bargaining Power: Evidence From a Panel of French Firms," CEPR Discussion Paper 3510.

[9] Djankov, S., R. La Porta, F. Lopez-de-Silanes and A. Shleifer (2002), “The Regulation of Entry,” Quarterly Journal of Economics 117, 1-37.

[10] Dunne, Timothy, Mark J. Roberts and Larry Samuelson (1988), "Patterns of Firm Entry and Exit in U.S. Manufacturing Industries," The RAND Journal of Economics, 19(4), 495-515.

[11] Ebell, M. and C. Haefke (2003), "Unions, Monopoly Rents, and Product Market Deregulation in Europe", mimeo.

[12] Faia, E. and C. Haefke (2003), “The Monetary Transmission Mechanism and Labor Market Institutions”, mimeo.

[13] Fonseca, R., Lopez-Garcia, P. and C. Pissarides (2001), 'Entrepreneurship, Start-up Costs and Unemployment," European Economic Review 45, 692-705.

[14] de Fontenay, C.C. and J.S. Gans (2003), "Organizational Design and Technology Choice under Intrafirm Bargaining: Comment," American Economic Review 93, 448-455.

[15] Galí, J., (1995), “ Non-Walrasian Unemployment Fluctuations,” NBER Working Paper 5337. 
[16] Gollin, D. (2002), “Getting Income Shares Right,” The Journal of Political Economy 110, 458-474.

[17] Gul, F. (1987), "Bargaining Foundations of Shapley Value ” Econometrica, 81-95.

[18] den Haan, W.J., C. Haefke, and G. Ramey, (2001), “Shocks and Institutions in a Job Matching Model," NBER Working Paper 8463.

[19] den Haan, W.J., G. Ramey, and J. Watson (2000), “Job Destruction and Propagation of Shocks," American Economic Review 90, 482-498.

[20] Hamermesh, D.S. and G.A. Pfann, (1996), “Adjustment Costs in Factor Demand,” Journal of Economic Literature 34, 1264-1292.

[21] Hosios, A.J. (1990), “On the Efficiency of Matching and Related Models of Search and Unemployment," Review of Economic Studies 57, 279-298.

[22] Krueger, A.B. and J.S. Pischke (1997), “Observations and Conjectures on the U.S. Employment Miracle,” BER Working Paper 6146.

[23] Ljungqvist, L. and T.J. Sargent (1998), “The European Unemployment Dilemma,” Journal of Political Economy 106, 514-550.

[24] Ljungqvist, L. and T.J. Sargent (2004), "European Unemployment and Turbulence Revisited in a Matching Model," Journal of the European Economic Association forthcoming.

[25] Mata, Jose and Pedro Portugal (1994), “Life duration of new firms,” Journal of Industrial Economics, 44, 227245.

[26] Nickell, S. (1999), “Product Markets and Labour Markets,” Labor Economics 6, 1-20.

[27] OECD Employment Outlook, June 2001.

[28] Peretto, P. (2000), “Market Power, Growth, and Unemployment,” Duke University Discussion Paper 00-21.

[29] Petrongolo, B. and Pissarides, C.A., (2001), "Looking into the Black Box: A Survey of the Matching Function," Journal of Economic Literature 39, 716-741.

[30] Pissarides, C.A. (2000), Equilibrium Unemployment Theory, 2nd edition, Cambridge, Mass: MIT Press.

[31] Pissarides, C.A. (2001), “Company Start-Up Costs and Employment,” CEP Discussion Paper 520.

[32] Spector, D. (2002), "Competition and the Capital-Labor Conflict," CEPREMAP-CNRS Working paper 2002-07.

[33] Seldeslachts, J. (2002), “Interactions between Product and Labor Market Reforms," Universitat Autonoma de Barcelona, mimeo. 
[34] Smith, E. (1999), ’Search, Concave Production and Optimal Firm Size," Review of Economic Dynamics 2, 456471.

[35] Stole, L. and J. Zwiebel (1996), "Intra-firm Bargaining under Non-Binding Contracts," Review of Economic Studies 63, 375-410.

[36] Stole, L. and J. Zwiebel (1996a), “Organizational Design and Technology Choice under Intrafirm Bargaining,” American Economic Review 86, 195-222.

[37] Stole, L. and J. Zwiebel (2003), “Organizational Design and Technology Choice under Intrafirm Bargaining: Reply," American Economic Review 93, 456-457.

[38] van Reenen, J., (1996), "The Creation and Capture of Rents: Wages and Innovation in a Panel of UK Companies," Quarterly Journal of Economics, 111, 195-226.

[39] Wagner, J. (1994), “The Post-Entry Performance of New Small Firms in German Manufacturing Industries,” Journal of Industrial Economics, 42(2), 141-54.

[40] Yashiv, E. (2001), "Wage Bargaining, the Value of Unemployment, and the Labor Share of Income," Tel Aviv University, mimeo. 


\section{A Proofs}

\section{A.1 Proof of Lemma 1}

Proof We need to establish that $\frac{\partial \theta}{\partial \xi}>0$. Applying the implicit function to equation (30) gives us:

$$
\frac{\partial \theta}{\partial \xi}=\frac{(1-\beta)}{(\xi-1)(\xi-\beta)} \frac{b+\frac{\beta}{1-\beta} \frac{\Phi_{V} \theta}{1-\delta}+\frac{1}{1-\beta} \frac{\Phi_{V}}{q(\theta)} \frac{r+\chi}{1-\delta}}{\frac{\beta}{1-\beta} \frac{\Phi_{V}}{1-\delta}-\frac{r+\chi}{1-\beta} \frac{\Phi_{V}}{1-\delta} \frac{q^{\prime}(\theta)}{[q(\theta)]^{2}}}>0
$$

The first term and the numerator of the second term are clearly positive since $\beta \in(0,1)$ and $\xi>1$. For a constant returns to scale Cobb-Douglas matching function $q^{\prime}(\theta)<0$, so that the denominator is also guaranteed to be positive.

\section{A.2 Proof of Proposition 1}

Proof (i) From (32) and applying Lemma 1, it is straightforward to show that $\frac{\partial u}{\partial \xi}<0$ whenever $q(\theta)+\theta q^{\prime}(\theta)>0$. This latter condition holds for all Cobb-Douglas constant returns to scale matching functions.

(ii) From (24), we obtain

$$
\frac{\partial \frac{w}{P}}{\partial \xi}=\frac{\beta}{1-\beta} \frac{\Phi_{V}}{1-\delta} \frac{\partial \theta}{\partial \xi}\left[1-\frac{(r+\chi) q^{\prime}(\theta)}{q(\theta)^{2}}\right]>0
$$

where the last inequality is due to Lemma 1 and the fact that $q^{\prime}(\theta)<0$ for any CRS Cobb-Douglas matching function.

\section{A.3 Proof of Proposition 2}

Proof (i) We need to establish that $\frac{\partial \theta}{\partial b}, \frac{\partial \theta}{\partial \Phi_{V}}, \frac{\partial \theta}{\partial r}, \frac{\partial \theta}{\partial \delta}$ and $\frac{\partial \theta}{\partial \widetilde{\chi}}$ are all negative. In each case, we apply the implicit function theorem to equation (30), to obtain $\frac{\partial \theta}{\partial x}=-\frac{\partial[\cdot]}{\partial x} / \frac{\partial[\cdot]}{\partial \theta}$ where $x$ is the relevant parameter and derivatives are taken with respect to the RHS of (30). It is easy to see that the denominator is positive for all constant returns to scale matching functions, so it remains to establish that the numerator $\frac{\partial[\cdot]}{\partial x}>0$ for all parameters $x$. We obtain:

$$
\begin{aligned}
\frac{\partial[\cdot]}{\partial b} & =\frac{\xi-\beta}{\xi-1}>0 \\
\frac{\partial[\cdot]}{\partial \Phi_{V}} & =\frac{\xi-\beta}{\xi-1}\left(\frac{\beta}{1-\beta} \frac{\theta}{1-\delta}+\frac{1}{1-\beta} \frac{r+\chi}{1-\delta} \frac{1}{q(\theta)}\right)>0 \\
\frac{\partial[\cdot]}{\partial r} & =\frac{\xi-\beta}{\xi-1}\left(\frac{1}{1-\beta} \frac{\Phi_{V}}{q(\theta)} \frac{1}{1-\delta}\right)>0 \\
\frac{\partial[\cdot]}{\partial \delta} & =\frac{\xi-\beta}{\xi-1}\left(\frac{\beta}{1-\beta} \frac{\delta}{(1-\delta)^{2}} \Phi_{V} \theta+\frac{1}{1-\beta} \frac{\Phi_{V}}{q(\theta)} \frac{1+r}{(1-\delta)^{2}}\right)>0 \\
\frac{\partial[\cdot]}{\partial \widetilde{\chi}} & =\frac{\xi-\beta}{\xi-1}\left(\frac{1}{1-\beta} \frac{\Phi_{V}}{q(\theta)}\right)>0
\end{aligned}
$$

(ii) $\frac{\partial u}{\partial b}, \frac{\partial u}{\partial \Phi_{V}}$ and $\frac{\partial u}{\partial r}$ can be shown to be positive by combining (i) with Lemma 1. For $\frac{\partial u}{\partial \widetilde{\chi}}$ and $\frac{\partial u}{\partial \delta}$ we obtain:

$$
\frac{\partial u}{\partial \widetilde{\chi}}=\frac{\theta q[\theta](1-\delta)-\chi \frac{\partial \theta}{\partial \widetilde{\chi}}\left[\theta q^{\prime}(\theta)+q(\theta)\right]}{[\chi+\theta q[\theta]]^{2}}
$$




$$
\frac{\partial u}{\partial \delta}=\frac{\theta q[\theta](1-\tilde{\chi})-\chi \frac{\partial \theta}{\partial \widetilde{\chi}}\left[\theta q^{\prime}(\theta)+q(\theta)\right]}{[\chi+\theta q[\theta]]^{2}}
$$

In both cases, the denominator is clearly positive, as is the first term of the numerator. It remains to show that the second term of the numerator is negative: this is indeed the case because we have established in (i) that $\frac{\partial \theta}{\partial \widetilde{\chi}}<0$ and because $\theta q^{\prime}(\theta)+q(\theta)>0$ for CRS Cobb-Douglas matching functions.

(iii) First, note that

$$
\frac{\partial[\cdot]}{\partial \beta}=\frac{\Phi_{V}}{q(\theta)} \frac{r+\chi}{1-\delta}\left(\frac{1}{1-\beta}\right)^{2}+\frac{\Phi_{V}}{1-\delta} \theta\left(\frac{1}{1-\beta}\right)^{2} \frac{\xi-\beta-\beta(1-\beta)}{\xi-1}-\frac{b}{\xi-1}
$$

In the perfect competition limit as $\xi \rightarrow \infty$, we have that $\frac{\partial[\cdot]}{\partial \beta}=\frac{\Phi_{V}}{q(\theta)} \frac{r+\chi}{1-\delta}\left(\frac{1}{1-\beta}\right)^{2}+\frac{\Phi_{V}}{1-\delta} \theta\left(\frac{1}{1-\beta}\right)^{2}>0$. Consider two mutually exclusive cases: $\frac{\partial[\cdot]}{\partial \beta}$ is either decreasing or increasing in $\xi$. In the former case, $\frac{\partial[\cdot]}{\partial \beta}>0$ at $\xi \rightarrow \infty$ ensures that $\frac{\partial[\cdot]}{\partial \beta}>0$ everywhere. We proceed by first showing that $\frac{\partial[\cdot]}{\partial \beta}$ is decreasing in $\xi$ whenever $b<\frac{\Phi_{V}}{1-\delta} \theta$. To see this, note that

$$
\frac{\partial^{2}[\cdot]}{\partial \beta \partial \xi}=-\frac{\Phi_{V}}{1-\delta} \theta \frac{1}{(\xi-1)^{2}}+\frac{b}{(\xi-1)^{2}}
$$

Clearly, $\frac{\partial^{2}[\cdot]}{\partial \beta \partial \xi}<0$ whenever $b<\frac{\Phi_{V}}{1-\delta} \theta$. This implies that if $b<\frac{\Phi_{V}}{1-\delta} \theta$, then $\frac{\partial \theta}{\partial \beta}<0$ and by Lemma $1 \frac{\partial u}{\partial \theta}>0$. In the latter, we can use that $\xi \in(1, \infty)$ and check whether $\frac{\partial[\cdot]}{\partial \beta}=0$ for a theshold value $\widetilde{\xi}$ which is in the admissible range $(1, \infty)$. Setting (41) equal to zero and solving for $\widetilde{\xi}$ gives us:

$$
\widetilde{\xi}=\frac{b(1-\beta)^{2}+\frac{\Phi_{V}}{1-\delta} \theta[\beta+\beta(1-\beta)]+\frac{\Phi_{V}}{q(\theta)} \frac{r+\chi}{1-\delta}}{\frac{\Phi_{V}}{q(\theta)} \frac{r+\chi}{1-\delta}+\frac{\Phi_{V}}{1-\delta} \theta}
$$

It is straightforward to see that whenever $b>\frac{\Phi_{V}}{1-\delta} \theta$, then $\widetilde{\xi}>1$ - so that $\frac{\partial[\cdot]}{\partial \beta}$ goes negative for some admissible value of $\xi \in(1, \infty)$. This implies that when $b>\frac{\Phi_{V}}{1-\delta} \theta$, then $\frac{\partial \theta}{\partial \beta} \leq 0$ for all $\xi \in[\widetilde{\xi}, \infty)$ and $\frac{\partial \theta}{\partial \beta}>0$ for all $\xi \in(1, \widetilde{\xi})$. The rest of the proof follows by applying Lemma 1. 


\section{B Tables}

Table 1: Entry Costs

\begin{tabular}{l|ccc|ccc}
\hline \multicolumn{1}{c|}{ Dataset } & \multicolumn{3}{c|}{ OECD } & \multicolumn{3}{c}{ Djankov, et. al. } \\
\hline \multicolumn{1}{c}{ Country } & Days & Procedures & Index & Days & Procedures & Fees \\
\hline Austria & 40 & 10 & 35.2 & 37 & 9 & $27.3 \%$ \\
Belgium & 30 & 7 & 25.6 & 33 & 8 & $10.0 \%$ \\
France & 30 & 16 & 39.3 & 53 & 15 & $14.3 \%$ \\
Germany & 80 & 10 & 55.2 & 42 & 10 & $15.7 \%$ \\
Greece & 32.5 & 28 & 58.7 & 36 & 15 & $58.6 \%$ \\
Italy & 50 & 25 & 62.9 & 62 & 16 & $20.0 \%$ \\
Netherlands & 60 & 9 & 43.7 & 31 & 8 & $18.4 \%$ \\
Portugal & 40 & 10 & 35.2 & 76 & 12 & $18.4 \%$ \\
Spain & 117.5 & 17 & 84.5 & 82 & 11 & $17.3 \%$ \\
Euro Average & $\mathbf{6 2 . 2}$ & - & $\mathbf{5 4 . 7}$ & $\mathbf{5 1 . 9}$ & - & $18.4 \%$ \\
United States & $\mathbf{7 . 5}$ & $\mathbf{3 . 5}$ & $\mathbf{8 . 6}$ & & $\mathbf{4}$ & $0.5 \%$ \\
\hline
\end{tabular}

The 'Days' column gives the number of business days necessary to start a new firm, while the 'Procedures' column gives the number of entry procedures which new firms must complete. The 'Index' column combines the 'Days' and 'Procedures' measures as (days + procedures/(ave procedures/day))/2, so that the indexes' units are days. The first two columns draw on 1997 data from Logotech S.A., as reported by the OECD [Fostering Entrepreneurship] and by Fonseca,et.al. (2001). The index is calculated as in Fonseca, et. al. (2001) but for a different (restricted) set of countries. The fourth and fifth column present the respective days and procedures measures reported by Djankov, et.al. (2002) for 1997. The sixth column gives Djankov, et.al. (2002)'s measure for fees required for entry, as a percentage of per capita GDP. 
Table 2: Calibration to U.S. data

\begin{tabular}{crl}
\hline$\beta$ & 0.5 & Worker bargaining power \\
$\eta$ & 0.5 & Elasticity of the matching function \\
$\bar{A}$ & 1 & Average level of labor productivity \\
$r$ & 0.00327 & $4 \%$ Annual interest rate \\
$b_{U S}$ & 0.274 & Real unemployment benefits, US \\
$b_{E u r o}$ & 0.554 & Real unemployment benefits, European \\
$\sigma$ & 2.0 & Substitution elasticity \\
$\chi$ & 0.0154 & Total separation rate \\
$\delta$ & 0.0100 & Probability of firm exit \\
$s$ & 0.2503 & Scaling parameter of the matching function \\
\hline
\end{tabular}


Table 3: Baseline Calibration, Policy Experiments I and II

\begin{tabular}{lcccc}
\hline & {$[1]$} & {$[2]$} & {$[3]$} & {$[4]$} \\
\hline & US $\Phi_{E}$, US $b$ & US $\Phi_{E}$, EU $b$ & EU $\Phi_{E}$, EU $b$ & EU $\Phi_{E}$, US $b$ \\
\hline Unemployment $u\left(\xi^{*}\right)$ & $5.53 \%$ & $8.32 \%$ & $8.74 \%$ & $5.82 \%$ \\
Labor market tightness $\theta\left(\xi^{*}\right)$ & 1.11 & 0.46 & 0.41 & 0.99 \\
Unemployment duration $\frac{1}{q(\theta)}$ & 3.8 & 5.9 & 6.2 & 4.0 \\
Vacancy duration $\frac{1}{\theta q(\theta)}$ & 4.2 & 2.7 & 2.6 & 4.0 \\
\hline Firm demand elasticity $\xi^{*}$ & 18.2 & 15.6 & 4.5 & 4.7 \\
Real net wage $\frac{w\left(\xi^{*}\right)}{P}\left(1-\tau_{I}\right)$ & 0.912 & 0.879 & 0.792 & 0.825 \\
Res. Utility $r V^{U}$ & 0.877 & 0.882 & 0.795 & 0.792 \\
Worker's Match Surplus & 0.043 & 0.027 & 0.026 & 0.041 \\
Profit per firm $\frac{\pi\left(\xi^{*}\right)}{P}$ & 0.0061 & 0.0063 & 0.0583 & 0.0588 \\
Markup & $2.9 \%$ & $3.4 \%$ & $14.3 \%$ & $13.4 \%$ \\
\hline Tax rates $\tau_{I}=\tau_{P}$ & $0.89 \%$ & $3.28 \%$ & $3.47 \%$ & $0.94 \%$ \\
Vacancy costs $\Phi_{V}$ & 0.547 & 0.547 & 0.547 & 0.547 \\
\hline Real unemployment benefit $b$ & 0.274 & 0.616 & 0.554 & 0.248 \\
Replacement rate & 0.30 & 0.70 & 0.70 & 0.30 \\
\hline
\end{tabular}

This table presents the equilibrium values for main variables of four economies. Column [1] gives results for the US economy, while column [3] gives results for the continental European economy. Columns [2] and [4] present hybrid economies. Column [2] gives results for the economy with low US entry costs but a high European replacement rate. Column [4] gives results for the economy with high European entry costs but a low US replacement rate. 
Table 4: Summary of Results and Robustness of Calibration to Entry Cost Data

\begin{tabular}{ccc}
\hline Policy Experiment & I & II \\
\hline$\Delta u[P M I]$ & $\mathbf{0 . 4 2} \%$ & $\mathbf{0 . 2 9} \%$ \\
$\Delta u$ & $\mathbf{3 . 2 1} \%$ & $\mathbf{3 . 2 1} \%$ \\
share $[P M I]$ & $\mathbf{1 3} \%$ & $\mathbf{9 \%}$ \\
\hline$\Delta$ net $w[P M I]$ & $\mathbf{0 . 0 8 8}$ & $\mathbf{0 . 0 8 7}$ \\
$\Delta n e t \_w$ & $\mathbf{0 . 1 2 0}$ & $\mathbf{0 . 1 2 0}$ \\
share $[P M I]$ & $\mathbf{7 3 \%}$ & $\mathbf{7 2} \%$ \\
$\%$ inc net $w$ & $\mathbf{1 1 \%}$ & $\mathbf{1 1} \%$ \\
\hline$\Delta \theta[P M I]$ & $\mathbf{0 . 0 4 6}$ & $\mathbf{0 . 1 1 5}$ \\
$\Delta \theta$ & $\mathbf{0 . 6 9 3}$ & $\mathbf{0 . 6 9 3}$ \\
share $[\theta]$ & $\mathbf{7 \%}$ & $\mathbf{1 7} \%$ \\
\hline
\end{tabular}

This table summarizes the results of policy experiments I and II. $\Delta u[P M I]$ is the change in the unemployment rate due to product market institutions, the difference between columns [3] and [2] for Experiment I and between [4] and [1] for Experiment II in Table 3. $\Delta u$ is the total change in the unemployment rate, the difference between [3] and [1]. share $[P M I]$ is equal to $\frac{\Delta u[P M I]}{\Delta u}$. The $\Delta$ net_wand $\Delta \theta$ variables are defined analogously, but of course refer to the changes in net (after-tax) real wages and equilibrium labor market tightness, respectively. Finally, \% inc net $w$ refers to the percentage increase in net real wages due to lower entry barriers. 


\section{Figures}

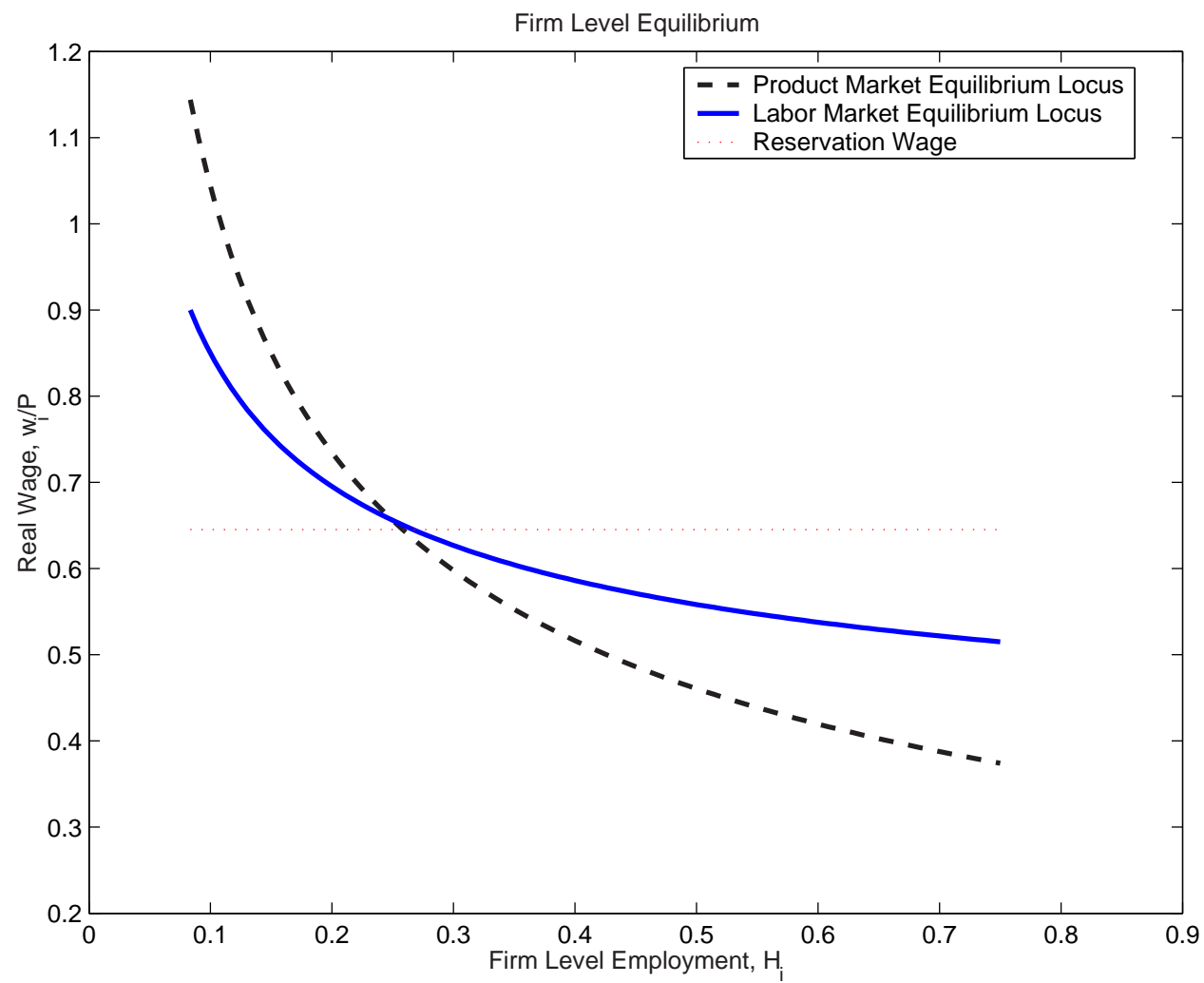

Figure 1: Firm-Level Equilibrium. 

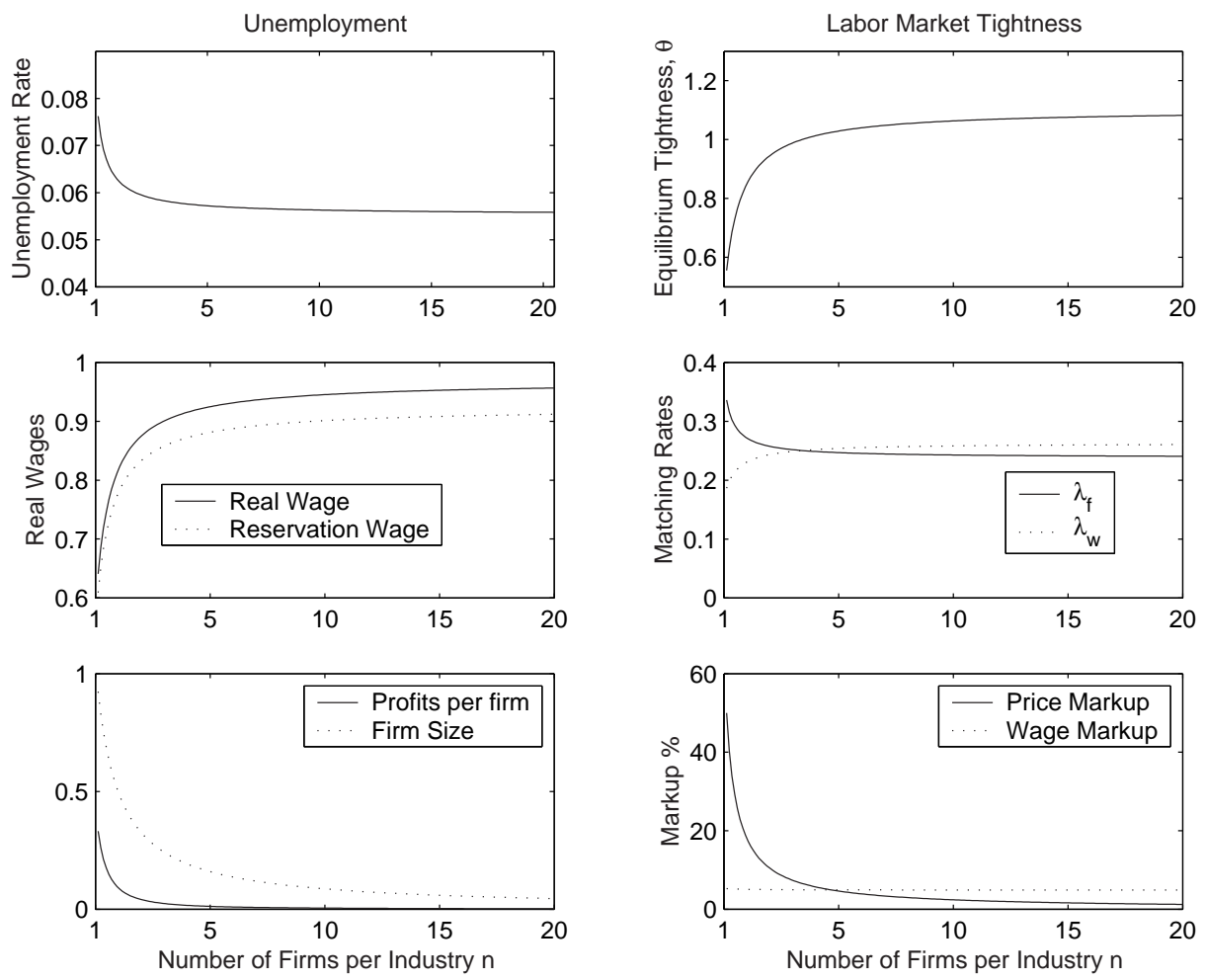

Figure 2: Effect of Firm Level Demand Elasticity on Model Outcomes. 


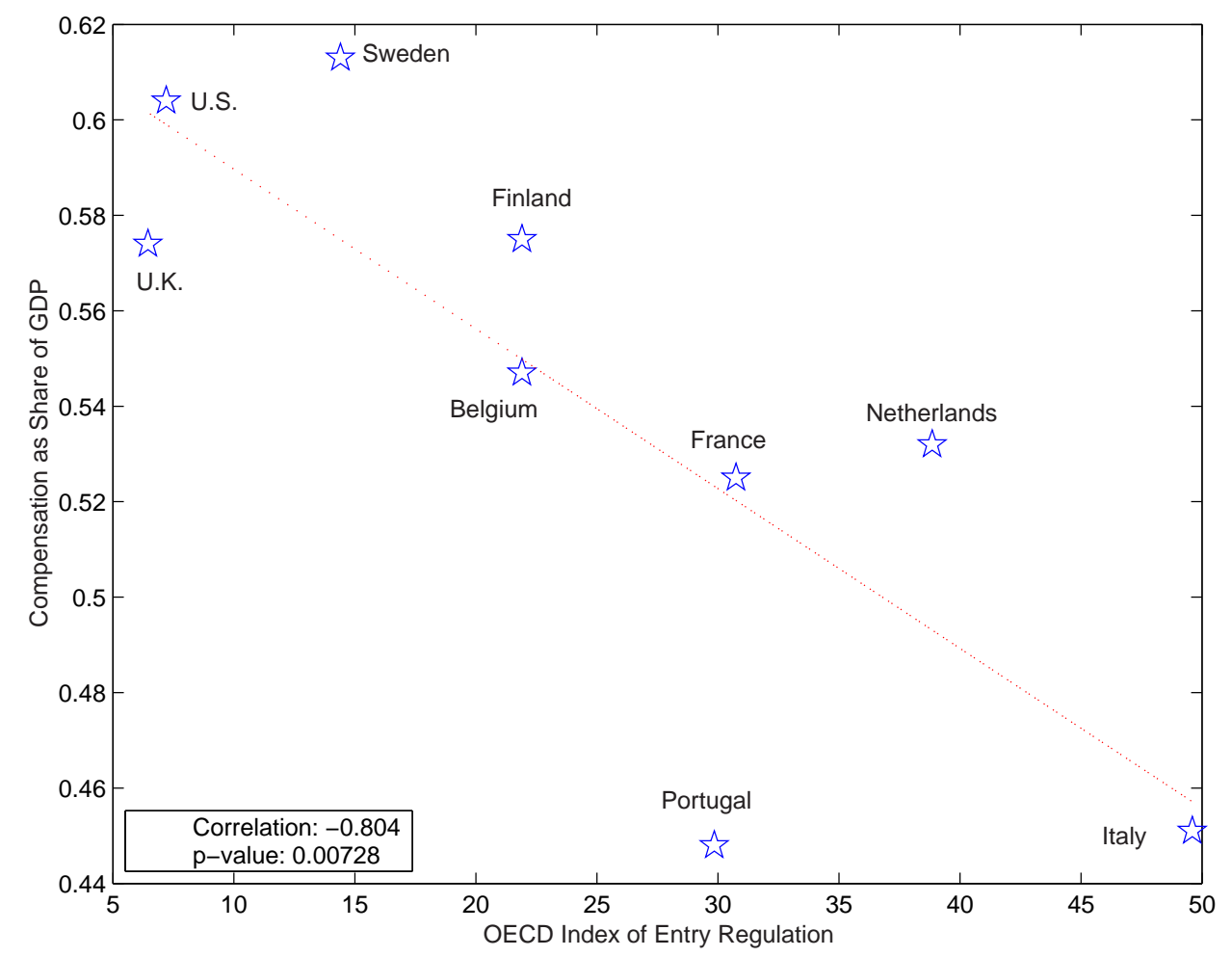

Figure 3: Entry Regulation and naive Labor Shares.

Data on compensation/GDP is taken from Gollin (2002), Table 2, column 4. Data on entry regulation is the regulation index of Fonseca et al. (2001), table 2, column 4, multiplied by 5 to convert to days. The negative correlation is highly significant even for the small number of observations. This plot is merely meant to be an illustration of the data. 


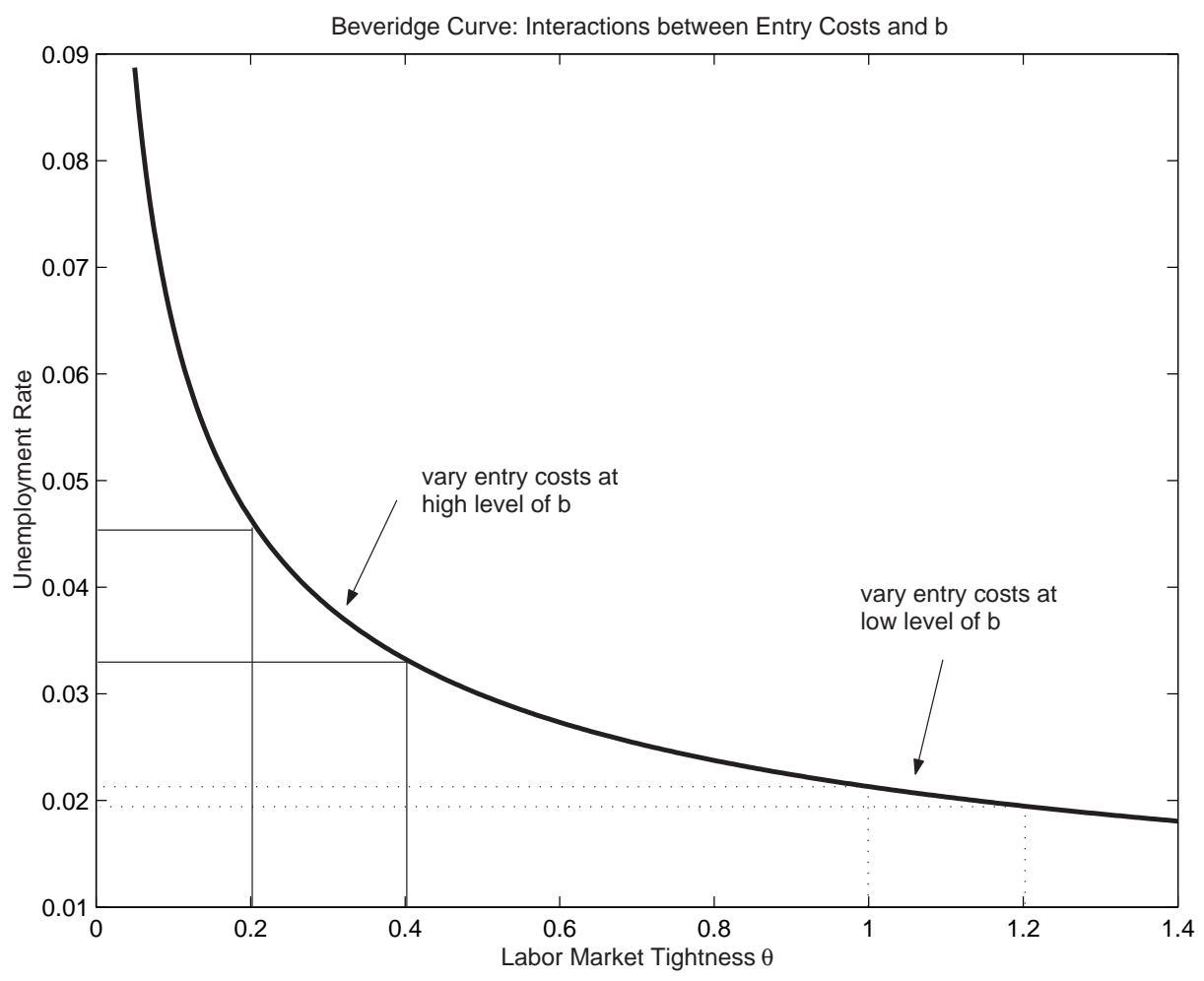

Figure 4: Beveridge Curve and potential interactions between entry costs and $b$. 

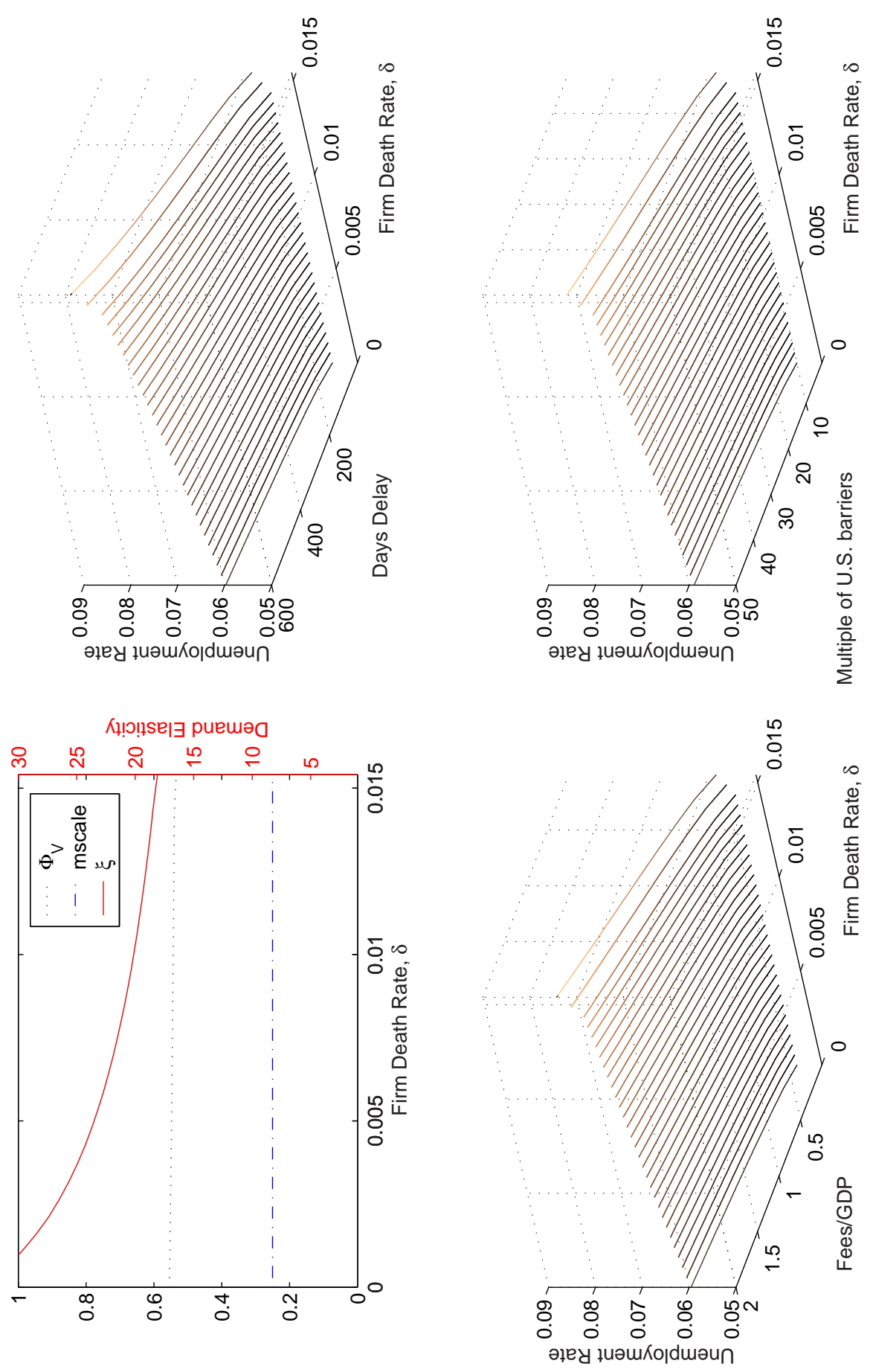

Figure 5: Firm Death Rate. 

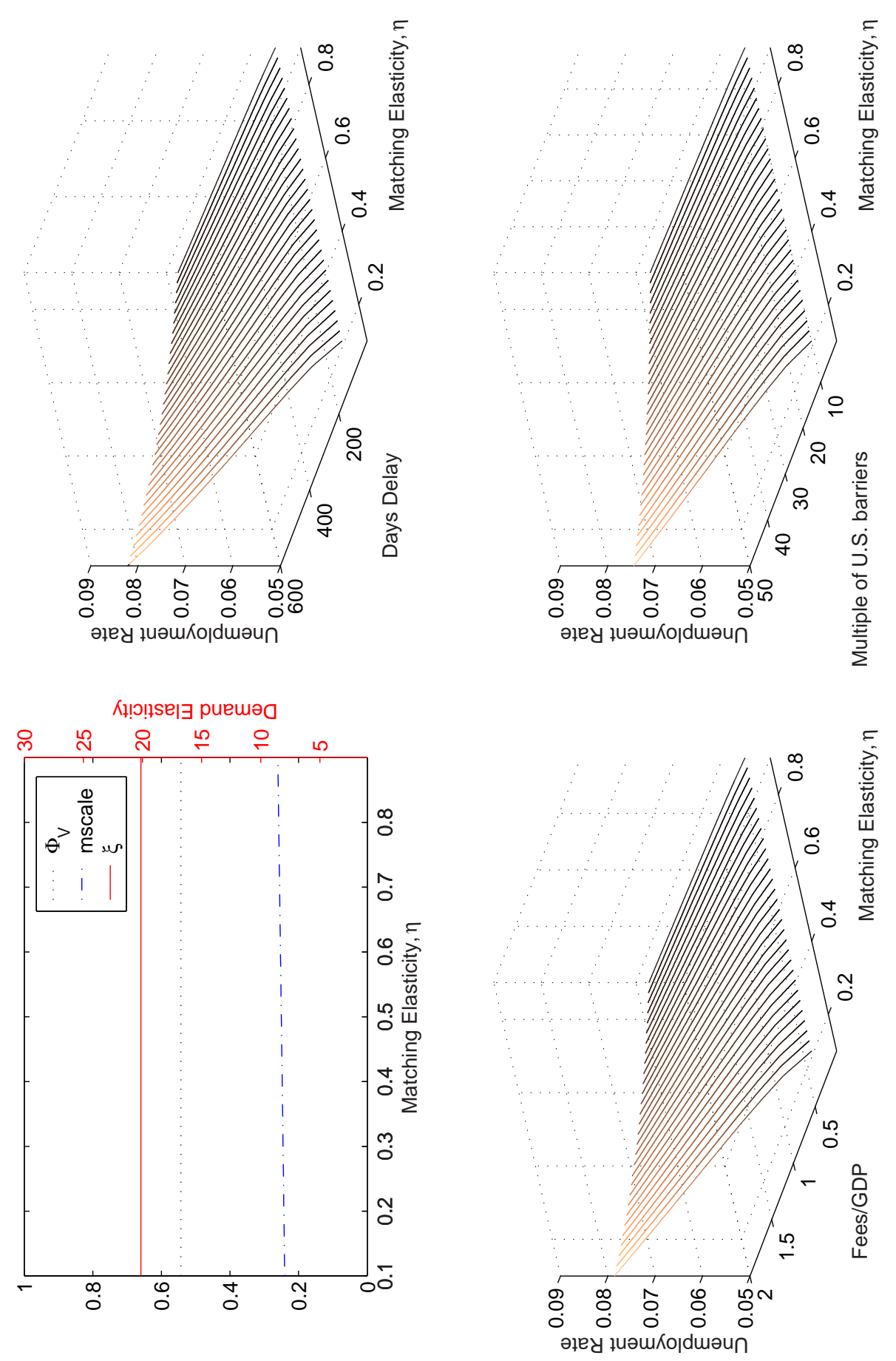

Figure 6: Matching Elasticity. 


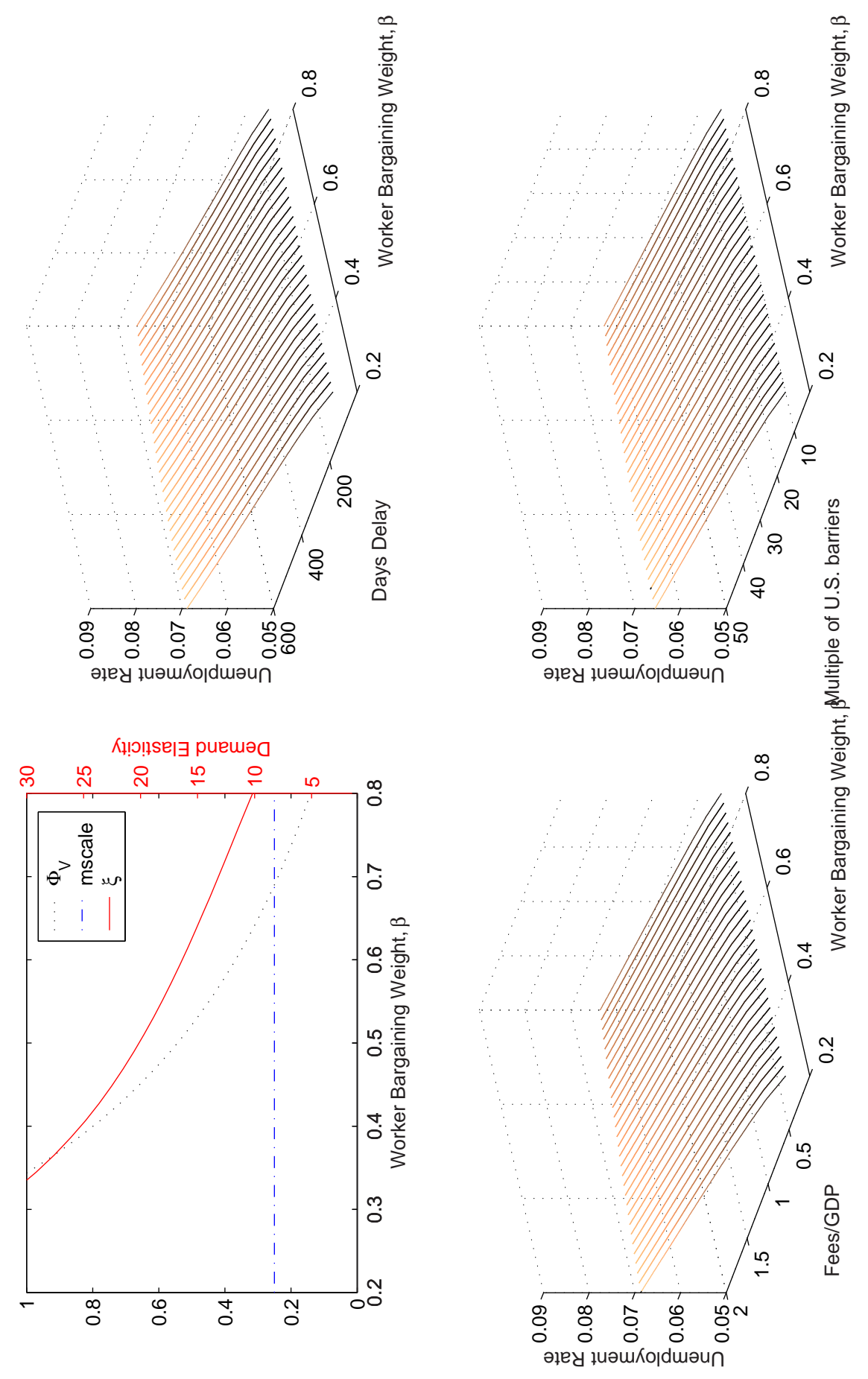

Figure 7: Bargaining Power. 